\title{
Spatiotemporal analysis of multiscalar drought characteristics across the Loess Plateau of China
}

\author{
Zhipeng Liu ${ }^{\mathrm{a}, *}$, Yunqiang Wang ${ }^{\mathrm{b}}$, Mingan Shao ${ }^{\mathrm{c}}$, Xiaoxu Jia ${ }^{\mathrm{c}}$, Xuelin $\mathrm{Li}^{\mathrm{a}}$ \\ ${ }^{a}$ College of Resources and Environmental Sciences, Nanjing Agricultural University, 1 Weigang, Nanjing 210095, PR China \\ ${ }^{\mathrm{b}}$ State Key Laboratory of Loess and Quaternary Geology, Institute of Earth Environment, Chinese Academy of Sciences, Xi'an, Shaanxi 710075, PR China

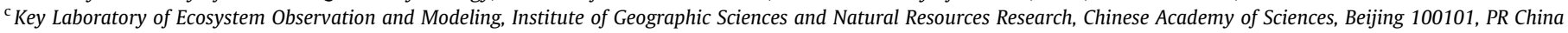

\section{A R T I C L E I N F O}

\section{Article history:}

Received 7 October 2015

Received in revised form 8 December 2015

Accepted 3 January 2016

Available online 12 January 2016

This manuscript was handled by Andras

Bardossy, Editor-in-Chief, with the

assistance of Alon Rimmer, Associate Editor

\section{Keywords:}

Drought severity

Spatial variation

Temporal trend

Evapotranspiration

Water resources

\begin{abstract}
S U M M A R Y
Drought is the most widespread and destructive hazard in arid and semiarid regions, with behaviors that become more complicated under climate change. To provide an overall view of drought conditions across the Loess Plateau of China, two multiscalar drought indices, the Standardized Precipitation Index (SPI) and the Standardized Precipitation Evapotranspiration Index (SPEI), were used to identify the regional spatiotemporal characteristics of drought conditions from 1957 to 2012. Climatic data from 54 meteorological stations across the region were used to calculate the SPI and SPEI time series at 1-, 3-, 6-, 12- and 24 -month time scales. Subregions with independent drought characteristics and the corresponding representative meteorological stations were identified by principal component analysis to facilitate regional drought monitoring. A temporal trend of drought severity over a 12-month time scale, as detected by the Mann-Kendall test, was mapped for the entire region. The intensity of the increasing trend of drought severity based on the SPEI was weaker than that based on the SPI. The area with a significant increasing trend of drought severity based on the SPEI was only found in the southwest of the region and was much smaller than that based on the SPI. The temporal behavior of drought frequency from January to December differed over different time scales and levels of drought severity. The regional distributions of the drought frequency were mapped for different months. Generally, the drought frequency spatially decreased from southeast to northwest and was higher in the middle of the winter, late spring and early summer. While the drought-hit area also changed with time, it was generally within the central and northwest areas of the region. Drought behaviors identified by the SPI and SPEI also changed with different time scales. Clear differences were also found among the drought characteristics identified by SPI, SPEI and the self-calibrated Palmer Drought Severity Index. The SPEI is considered as a robust index for regional drought monitoring and analysis under global climate change scenarios because of its multiscalar nature, simple form, low data requirement, and ability to identify the effects of temperature on drought conditions.
\end{abstract}

(c) 2016 Elsevier B.V. All rights reserved.

\section{Introduction}

Drought is a silent, progressive and recurrent natural hazard that leads to substantial agricultural, economic, and environmental damage in both dry and wet regions across the world (Wilhite, 1993; Li et al., 2013). Drought is generally considered as a negative water imbalance caused by a sustained lack of precipitation/available water resources or excess evapotranspiration over an extended period of time (Wilhite and Glantz, 1985; McKee et al., 1993). Although drought cannot be avoided, accurate information on its spatiotemporal characteristics is indispensable to the devel-

\footnotetext{
* Corresponding author.
}

opment of drought contingency plans for mitigating potential impacts. However, given the various definitions of drought and its great variability in space and time, it is difficult to objectively quantify the characteristics of drought in terms of intensity, magnitude, duration, and spatial extent (Heim, 2002).

In the past several decades, numerous studies have committed to develop objective indices to determine the onset, ending point and severity of drought for drought quantification, effective monitoring and establishment of early-warning systems (Heim, 2002). Most of the indices were based on meteorological variables, especially the deviation of precipitation from historically established norms. Among the various applied drought indices, the Palmer Drought Severity Index (PDSI) was a landmark for drought quantification (Palmer, 1965; Heim, 2002). It is based on 
a supply-and-demand concept expressed by a monthly water balance equation for a two-layer model that involves precipitation, runoff, evapotranspiration and soil moisture (Palmer, 1965). The PDSI and its variations such as the modified PDSI (PMDI), the Palmer Hydrological Drought Index (PHDI) and the Z Index have been extensively used in drought monitoring and integrated water resources management (Heddinghaus and Sabol, 1991; Guttman et al., 1992; B. Zhang et al., 2012; T. Zhang et al., 2012; Zhao and Wu, 2013). Nevertheless, the Palmer indices have several inherent deficiencies that limit their ability to capture the spatiotemporal characteristics of drought. First, their results are greatly influenced by the chosen calibration period, and thus their utility is limited in the corresponding areas. This makes the Palmer indices spatially variant and not suitable for spatial comparisons of drought characteristics, especially in large-scale studies (Guttman et al., 1992). Although the spatially comparable self-calibrated PDSI (sc-PDSI) was developed by Wells et al. (2004) to overcome the above problem, the main inherent shortcoming of PDSI, the fixed time scale, has not been resolved. Additionally, the inherent 9- to 12-month time scale of PDSI makes it impossible to recognize the drought characteristics of multiple time scales that reflect the relationships with different usable water sources such as soil moisture, ground water, snowpack, stream flow and reservoirs (McKee et al., 1993).

To represent drought in a better manner than that of the Palmer indices, a spatially invariant and multiscalar index, the Standardized Precipitation Index (SPI), was developed by McKee et al. (1993). The SPI calculation is based on a long-term precipitation record, which is first fitted to a probability distribution and then transformed through an equal-probability transformation into a normal distribution (Guttman, 1999). The standardization ensures that the SPI values can be compared among different study sites. Moreover, the SPI can be calculated at different time scales, from one month to several years, defined by the users. This versatility allows it to monitor water deficits for different hydrological systems as responses to abnormal precipitation, including shortterm water supplies such as soil moisture that are important for agricultural production and long-term water resources such as ground water supplies, stream flow and reservoir levels (McKee et al., 1993). These advantages of the SPI have promoted its global acceptance as a robust drought monitoring tool, and it has thus been accepted by the World Meteorological Organization as the reference drought index. Guttman (1997) compared the spectral characteristics of the PMDI with those of the SPI for several time scales. He recommended the simple and probabilistic SPI as the primary drought index rather than the complex and scale-fixed PDSI. By using the SPI, Hayes et al. (1999) monitored the severe 1996 drought in the Southern Great Plains and southwestern United State. They found that the SPI could identify the drought onset and severity one month in advance of the PDSI. Lloyd-Hughes and Saunders (2002) also compared the abilities of the SPI and PDSI in monitoring large-scale drought over the Europe and concluded that the SPI provided a more appropriate spatial standardization than the PDSI. In preserving the rarity of extreme drought events, the SPI also performed better than the Palmer indices (Hayes et al., 1999; Keyantash and Dracup, 2002; Steinemann, 2003). However, there are also some issues that need to be noted when using the SPI, such as its sensitivity to the precipitation record length (Wu et al., 2005), the selection of probability model and the procedure used in the estimation of its parameters (Guttman, 1999; Núñez et al., 2014). Moreover, the main criticism of the SPI is that it only includes the effect of precipitation on drought, while other influencing variables such as temperature, wind speed, evapotranspiration, and soil water holding capacity are not taken into consideration. Notably, the measured and predicted temperature datasets both show a marked increasing trend during the last 150 years into the 21st century (Jones and Moberg, 2003;
Solomon et al., 2007). Apparently, in the context of global warming, the variability of temperature must show important effects on drought conditions, as it can dramatically change the land surface water balance by controlling evapotranspiration (Sheffield and Wood, 2008).

Recently, Vicente-Serrano et al. (2010) formulated a new drought index, the Standardized Precipitation Evapotranspiration Index (SPEI), to further identify drought characteristics by considering the temperature effect on drought as well as representing the multiscalar nature of drought. The SPEI is based on a monthly climatic water balance, calculated as precipitation minus potential evapotranspiration (PET). The inclusion of evapotranspiration in the water balance calculation is the key point that allows the SPEI to identify the influences of fluctuations and trends of temperature and evapotranspiration on drought conditions in the context of global warming. This fact has been demonstrated by studies conducted in different climatic zones around the world (VicenteSerrano et al., 2010; Potop et al., 2012; Li et al., 2013; Jiang et al., 2014).

The Loess Plateau region covers a large area in the northwest of China, and it has been one of the most important agricultural regions for thousands of years. However, drought hazards occur frequently in this region and have caused huge agricultural and socio-economic losses (Yao et al., 2013). Severe water scarcity is the key obstacle for the healthy and sustainable development of ecological environment of the Loess Plateau (Shi and Shao, 2000). The unevenly distributed precipitation over the year also causes the Loess Plateau to suffer from the most severe soil erosion in the world. To control soil erosion, intensive vegetation restoration over large areas was supported by many scientists and policymakers, even though this might lead to increased transpiration that can aggravate water shortages (Wang et al., 2011). Climate change and land use conversion together may make the drought conditions more complicated across the region. Comprehensive information on the spatiotemporal characteristics of drought conditions is therefore indispensable to guaranteeing food security and the success of ecological restoration on this region. Many studies have been conducted on this region to quantify and monitor the drought conditions using different drought indices. By combing the Variable Infiltration Capacity (VIC) model and PDSI, B. Zhang et al. (2012) and Zhao and Wu (2013) analyzed the drought variation trends in six subregions of the Loess Plateau over the past four decades (1971-2010). Using the compound index of meteorological drought (CI), T. Zhang et al. (2012) investigated the rate, intensity and frequency of drought conditions of the past 50 years in Gansu province located in the southwest of Loess Plateau. They found a significant increasing trend of the drought rate in the spring and autumn and a slight increasing trend in the summer and winter. Based on climatic data from 1961 to 2010 collected from 48 meteorological stations distributed across the Loess Plateau, Yao et al. (2013) identified the decadal variation and the spatiotemporal distribution of spring droughts using a drought level index based on relative humidity. They concluded that the area affected by drought increased at a speed of $4 \%$ per decade and currently covered $94 \%$ of the Loess Plateau. They also projected that the area and intensity of drought would keep increasing over the next several years. Based on the climate data from five meteorological stations, Jiang et al. (2014) simulated the drought severity using four different drought indices with hypothetical progressive climate change conditions, i.e., the PDSI, sc-PDSI, SPI and SPEI, in the Shaanxi province on the Loess Plateau. They concluded that the drought severity could increase with the decline of precipitation and the increase of temperature. Although these previous studies provided reliable results, their perspectives were limited by either the spatial extent or the temporal scale of the original meteorological data, so they could not provide an overall view of 
the drought characteristics across the entire Loess Plateau, which is necessary for the formulation of regional agricultural and environmental policy. Moreover, constrained by the drought indices they used, the multiscalar nature of the drought conditions was not well represented, and the variation trends at different temporal and spatial scales were not investigated so far.

Therefore, the objectives of the present study were (1) to provide a regional view of the spatiotemporal characteristics of drought conditions across the entire Loess Plateau by using multiscalar drought indices, i.e., SPI and SPEI; and (2) to identify the variability and trends of drought at different spatial and temporal scales under climate change conditions.

\section{Materials and methods}

\subsection{Study area}

The Loess Plateau region, located in the northwest of China, covers an area of approximately $62.4 \times 10^{4} \mathrm{~km}^{2}\left(34-45^{\circ} 5^{\prime} \mathrm{N}, 101-11\right.$ $4^{\circ} 33^{\prime} \mathrm{E}$ ), traversed by the upper-middle reaches of the Yellow River (Fig. 1a). It starts from the TaiHang Mountains in the east, reaches the RiYue Mountain in the west, and borders on the QinLing Mountains in the south and Yin Mountain in the north. The region lies in the marginal zone of the East Asian and South Asian summer monsoon and thus is sensitive to the activity and intensity of the monsoon (Yao et al., 2013). The annual precipitation ranges from $150 \mathrm{~mm}$ in the northwest to $800 \mathrm{~mm}$ in the southeast, $55-78 \%$ of which falls from June to September in the form of high-intensity storms. The annual mean temperature ranges from $3.6^{\circ} \mathrm{C}$ in the northwest to $14.3^{\circ} \mathrm{C}$ in the southeast. There is a large diurnal temperature range over the year, with dry and cold winters, hot and humid summers, a rapid temperature reduction in the autumn, and a rapid temperature rise in the spring. Solar radiation is abundant, with 2200-2800 annual hours of sunshine and 5.0$6.3 \times 10^{9} \mathrm{~J} / \mathrm{m}^{2}$ annual total solar heat gain. The annual potential evaporation was estimated to be much higher than the precipitation, ranging from $865 \mathrm{~mm}$ to $1274 \mathrm{~mm}$ (Li et al., 2012).

The loessial landforms include yuans (large flat surfaces with little erosion), ridges, hills and gullies at elevations ranging from 200 to $3000 \mathrm{~m}$ (Fig. 1b). The loess-paleosol deposits range from 30 to $80 \mathrm{~m}$ in thickness. The soils are mainly derived from loess deposits and develop into diverse types. Most of the soils are clay-loam in texture, being sandier in the northwest and clayier in the southeast (Wang et al., 2014a). Natural vegetation has been largely destroyed by deforestation and cultivation. Generally, the vegetation zones change with the precipitation from southeast to northwest in the order of forest, forest-steppe, typical-steppe, desert-steppe, and steppe-desert zones. Due to the uneven distribution of precipitation, strong evaporation and poor vegetation coverage, the Loess Plateau has suffered from severe water shortages, serious soil erosion and land degradation (Shi and Shao, 2000). Since the 1990s, the Chinese government has initiated a series of environmental restoration and protection programs in this region, such as the "Grain-for-Green" project that aimed at deceasing cultivation on steep slopes by encourage farmers to plant trees and grass instead of grain crops (Ostwald and Chen, 2006). By the end of 2007, the population in this region has reached 0.11 billion, with a population density ranging from 4 people $/ \mathrm{km}^{2}$ to 3289 people $/ \mathrm{km}^{2}$ (Liu et al., 2012).

\subsection{Data collection and preparation}

The secular series of several climatic variables, including monthly average values of precipitation, air temperature, wind speed, vapor pressure, bright sunshine duration, relative humidity, and monthly maximum and minimum values of air temperature, were obtained from the China National Meteorological Centre (CNMC) for 71 meteorological stations distributed across the entire Loess Plateau region (Fig. 1c). Moreover, the longitude, latitude, and elevation above sea level of each station were recorded. Given that these stations were not established in the same year and some of them went out of service for various reasons, the lengths of the records were different, ranging from 12 years (1989-2001) to 62 years (1951-2012). With the help of geographic information system, the data of the Available Soil Water Holding Capacity (ASWHC) of the soil at each station was extracted according to its coordinate from the regional digital ASWHC surface, interpolated based on intensive field sampling and measurements in 2008 (Wang et al., 2014a,b). To ensure a sufficient length and quality of the data series, meteorological data sets from 54 stations were used for further drought analysis, covering a period of 56 years from January of 1957 to December of 2012. The data series were carefully checked, and there were no missing data.

\subsection{Drought indices}

Two drought indices, i.e., the SPI and SPEI, were employed to represent the multiscalar characteristics of drought on the Loess Plateau, as well as to facilitate the comparison of different locations across the region. The self-calibrated Palmer Drought Severity Index (sc-PDSI) was also calculated to compare with the SPI and SPEI. The background theory and detailed methodology for computing these drought indices has been extensively described in several reports (Mckee et al., 1993; Guttman, 1999; Wells et al., 2004; Vicente-Serrano et al., 2010). Here, for the sake of completeness, the main steps for their calculation are described below.

\subsubsection{SPI}

The SPI calculation for a specific time scale and location only requires a long-term monthly precipitation series. The first step is to find the probability density function that best describes the distribution of the precipitation data for a selected time scale. Here, for each meteorological station, the precipitation data of 668 months was fitted to a Gamma distribution function, which is defined as

$g(x)=\frac{1}{\beta^{\alpha} \Gamma(\alpha)} x^{\alpha-1} e^{-x / \beta} \quad$ for $x>0$

where $\alpha>0$ is a shape parameter, $\beta>0$ is a scale parameter, $x$ is the precipitation amount, and $\Gamma(\alpha)$ is the gamma function. For $\alpha>0$, the gamma function is defined by

$\Gamma(\alpha)=\int_{0}^{\infty} x^{\alpha-1} e^{-x} d x$

The two parameters $\alpha$ and $\beta$ were estimated through a maximum likelihood estimation using the approximation of

$\hat{\alpha}=\frac{1}{4 A}\left(1+\sqrt{\frac{4 A}{3}}\right)$

$\hat{\beta}=\frac{\bar{x}}{\hat{\alpha}}$

where

$A=\ln (\bar{x})-\frac{\sum \ln (x)}{n}$

Here, $n$ is the number of the observations in the precipitation data. Integrating the probability density function with respect to $x$ and attaching the two estimated parameters $\alpha$ and $\beta$ yields the cumulative probability distribution function $G(x)$ : 


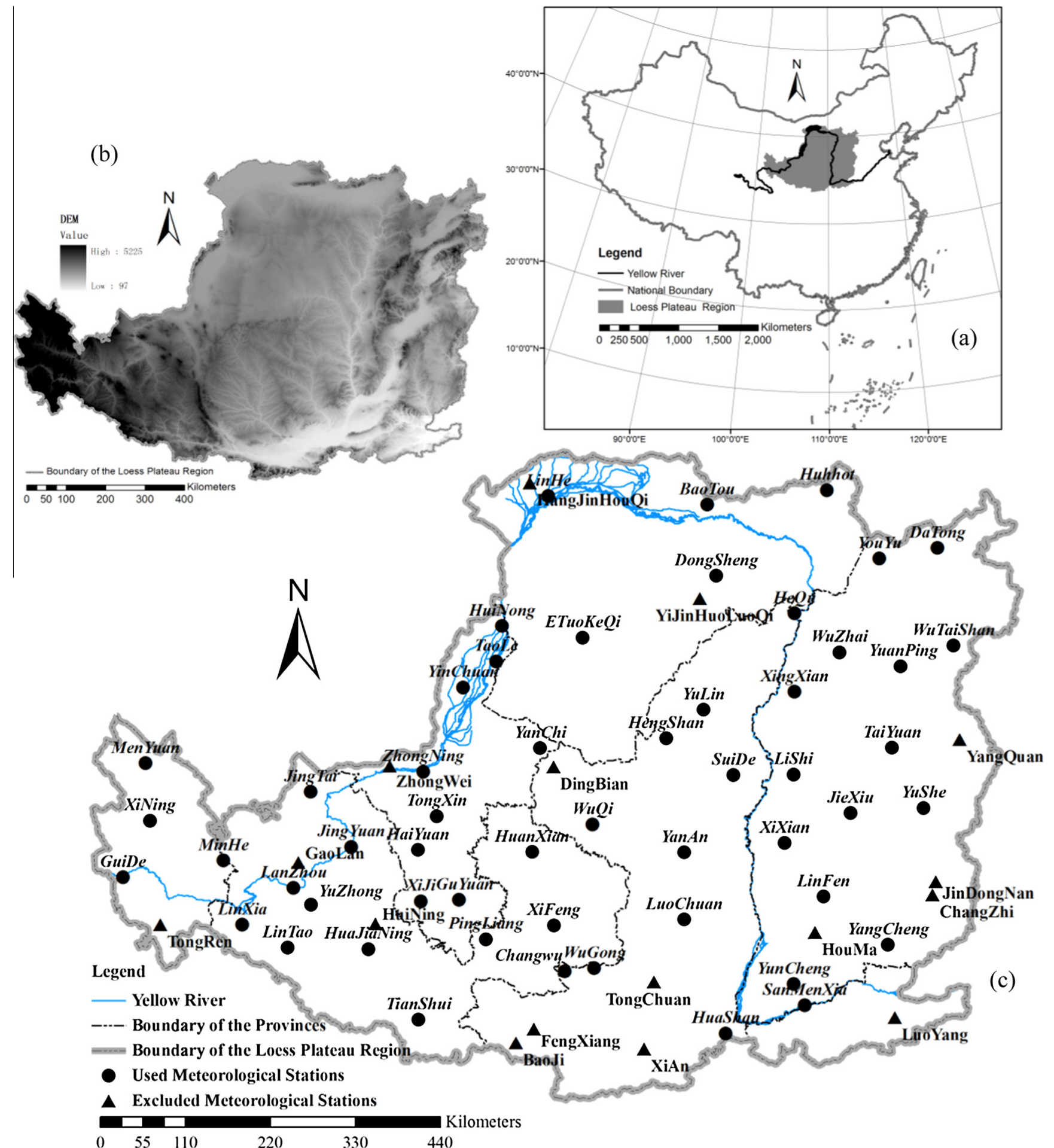

Fig. 1. Location (a) and digital elevation map (b) of the Loess Plateau in China and the 71 meteorological stations (c) distributed across the region.

$G(x)=\int_{0}^{x} g(x) d x=\frac{1}{\hat{\beta}^{\hat{\alpha}} \Gamma(\hat{\alpha})} \int_{0}^{x} x^{\hat{\alpha}} e^{-x / \hat{\beta}}$

Letting $t=x / \hat{\beta}$ yields the incomplete gamma function:

$G(x)=\frac{1}{\Gamma(\hat{\alpha})} \int_{0}^{x} t^{\hat{\alpha}-1} e^{t} d t$
Because the gamma function is undefined for $x=0$ and the precipitation distribution may contain zeros, the cumulative probability becomes

$H(x)=q+(1-q) G(x)$

where $q$ is the probability of zero precipitation, calculated as

$q=\frac{m}{n}$ 
where $m$ is the number of instances of zero precipitation in the data series. $H(x)$ is then converged into the standard normal SPI variable using the following approximation (Abramowitz and Stegun, 1965):

$\mathrm{SPI}= \begin{cases}-\left(t-\frac{c_{0}+c_{1} t+c_{2} t^{2}}{1+d_{1} t+d_{2} t^{2}+d_{3} t^{3}}\right) & \text { for } 0<H(x) \leqslant 0.5 \\ +\left(t-\frac{c_{0}+c_{1} t+c_{2} t^{2}}{1+d_{1} t+d_{2} t^{2}+d_{3} t^{3}}\right) & \text { for } 0.5<H(x) \leqslant 1.0\end{cases}$

where $t$ is determined as

$t= \begin{cases}\sqrt{\ln \left(\frac{1}{(H(x))^{2}}\right)} & \text { for } 0<H(x) \leqslant 0.5 \\ \sqrt{\ln \left(\frac{1}{(1-H(x))^{2}}\right)} & \text { for } 0.5<H(x) \leqslant 1.0\end{cases}$

The coefficients $c_{0}, c_{1}, c_{2}, d_{1}, d_{2}$ and $d_{3}$ are the following constants:

$c_{0}=2.515517 \quad c_{1}=0.802853 \quad c_{2}=0.010328$

$d_{1}=1.432788 \quad d_{2}=0.189269 \quad d_{3}=0.001308$

The SPI at a given location can be calculated for different temporal scales. Here, five time scales, i.e., 1, 3, 6, 12 and 24-month, were considered to provide multiscalar information on drought characteristics and their impact on different segments of the hydrological cycle on the study region.

According to Mckee et al. (1993), the drought severity can be classified into five classes based the SPI values, i.e., non-drought when the SPI $\geqslant 0$, mild drought when $-1<\mathrm{SPI}<0$, moderate drought when $-1.5<\mathrm{SPI} \leqslant-1$, severe drought when $-2.0<\mathrm{SPI} \leqslant-1.5$, and extreme drought when SPI $\leqslant-2.0$.

\subsubsection{SPEI}

The SPEI calculation is based on the original SPI calculation procedures. The difference between the SPI and SPEI calculations is that the SPI only uses monthly precipitation as the input data, while the SPEI uses the monthly difference between precipitation and potential evapotranspiration (PET) (Vicente-Serrano et al., 2010). Thus, the first step is to calculate the PET, which is influenced by many factors such as the surface temperature, air humidity, soil incoming radiation, water vapor pressure, groundatmosphere latent and sensible heat fluxes (Allen et al., 1994). Various methods have been proposed to indirectly estimate the PET using meteorological parameters. Among them, the physically based Penman-Monteith method (PM) has been adopted widely as the standard procedure for PET calculation by many associations, such as the International Commission on Irrigations and Drainage (ICID), the Food and Agriculture Organization of the United Nations (FAO), and the American Society of Civil Engineers (ASCE). Its calculation requires many types of meteorological data such as solar radiation, temperature, wind speed and relative humidity. In our study, the PET was estimated by the PM method using the original parameterization of Allen et al. (1994), corresponding to a short reference crop of $0.12 \mathrm{~m}$ in height. Because the data of incoming solar radiation was not available at these meteorological stations, it was estimated from the bright sunshine duration. The saturation water pressure was estimated from the relative humidity. The atmospheric surface pressure required for computing the psychrometric constant was calculated from the atmospheric pressure at sea level and the elevation.

The probability distribution of the simple monthly water balance $D$, i.e., precipitation minus PET, was fitted to a threeparameter log-logistic function suggested by Vicente-Serrano et al. (2010), which is expressed as

$F(x)=\left[1+\left(\frac{\alpha}{x-\gamma}\right)^{\beta}\right]^{-1}$ where $\alpha, \beta$ and $\gamma$ are the scale, shape and origin parameters, respectively. It has been demonstrated that the $F(x)$ values for the $D$ series at different time scales adapt very well to the empirical $F(x)$ values at different observation sites, independent of the climate characteristics and the time scale of the analysis (Vicente-Serrano et al., 2010). In our study, these three parameters were obtained using the L-moment procedure, which is the most robust and easy approach (Ahmad et al., 1988). The parameters were calculated as

$\beta=\frac{2 w_{1}-w_{0}}{6 w_{1}-w_{0}-6 w_{2}}$

$\alpha=\frac{\left(w_{0}-2 w_{1}\right) \beta}{\Gamma\left(1+\frac{1}{\beta}\right) \Gamma\left(1-\frac{1}{\beta}\right)}$

$\gamma=w_{0}-\alpha \Gamma\left(\frac{1+1}{\beta}\right) \Gamma\left(\frac{1-1}{\beta}\right)$

where $w_{s}$ is the probability-weighted moments (PWMs) of order $s$, $s=0,1,2$.

$w_{S}=\frac{1}{N} \sum_{i=1}^{N}\left(1-F_{i}\right)^{s} D_{i}$

and $F_{i}$ is a frequency estimator calculated as

$F_{i}=\frac{i-0.35}{N}$

where $i$ is the range of observations arranged in increasing order and $N$ is the number of data points. Then, the SPEI was calculated as the standardized values of $F(x)$, following the same calculation used to calculate the SPI, described in Section 2.3.1.

As for the SPI, the SPEI has an average value of 0 and a standard deviation of 1 . The criteria of the drought severity classification are the same as that used for the SPI (Section 2.3.1). In our study, the calculations of the SPI and SPEI were performed with the "SPEI" package in R studio software (http://sac.csic.es/spei).

\subsubsection{Self-calibrated PDSI}

Based on the PDSI, the sc-PDSI uses dynamically calculated values to replace empirical constants in the PDSI algorithm, which makes it homogeneously spatially comparable. Given that the multiscalar characteristics of drought conditions cannot be represented by the sc-PDSI, the detailed background theory and steps of calculating the sc-PDSI are not described explicitly here. However, they can be found elsewhere (Palmer, 1965; Wells et al., 2004; Jiang et al., 2014). The calculation needs to quantify the evaporation, soil recharge, runoff, and water loss of the soil layer. However, these variables rely heavily on an important soil physical parameter, i.e., the available soil water holding capacity (ASWHC), the acquisition of which was described in Section 2.2 .

According to Palmer (1965) and Wells et al. (2004), the drought severity can be classified into six classes based the sc-PDSI values, i.e., non-drought when sc-PDSI $>0.5$; incipient drought when $-1.0<$ sc-PDSI $\leqslant 0.5$; mild drought when $-1.0 \leqslant$ sc-PDSI $<-2.0$, moderate drought when $-2.0 \leqslant \mathrm{sc}-\mathrm{PDSI}<-3.0$, severe drought when $-3.0 \leqslant$ sc-PDSI $<-4.0$, and extreme drought when sc-PDSI $\leqslant$ -4.0 .

\subsection{Statistical method}

\subsubsection{Descriptive statistics}

Basic statistical parameters, i.e., maximum, minimum and mean, were used to represent the monthly and annual distribution trends of the original precipitation and temperature data at these 54 selected meteorological stations. The coefficient of variation (CV\%), the ratio of the standard deviation to the mean, was 
calculated to describe the overall spatial and temporal variations of precipitation and temperature over the 56-year time span.

\subsubsection{Principal component analysis}

Given the large number of calculated drought index data for different locations and time periods, principal component analysis (PCA) was applied on the SPI and SPEI time series for dimension reduction and structural information extraction. The loadings for each meteorological station and scores for each principal component were also calculated according to the covariance matrix and the eigenvalues and eigenvectors of the SPI and SPEI time series. To detect more localized spatial variability of drought, the loadings were rotated with the Variance-Max method to obtain rather independent principal components (von Storch and Zwiers, 1999). According to North et al. (1982), the sampling errors of the eigenvalues associated with the principal component were estimated to determine the number of leading components retained for rotation. In our study, for both the SPI and SPEI time series, the first four eigenvalues were well separated within a 95\% confidence level. Thus, the variation of drought conditions across the Loess Plateau region could be represented by the first four principal components. The time series of scores for each rotated principal component (RPC) could represent the common temporal behavior of the SPI and SPEI time series in the areas with maximum loadings (Raziei et al., 2009).

The results of PCA were used to identify the representative locations and subregions with different types of drought characteristics. This information can help to provide a further regional view of drought conditions across the entire region, while taking into account the internal spatial variation. In this paper, the PCA results over the 12-month time scale (SPI-12 and SPEI-12) are discussed. This is because the annual time scale could avoid seasonal cycles while keeping the inter-annual variability by the memory effect (Raziei et al., 2009).

\subsubsection{Trend analysis}

The Mann-Kendall test has been widely used in environmental studies for temporal trend analysis (Gocic and Trajkovic, 2013; Tabari et al., 2014). In the present study, the Mann-Kendall test was performed to detect temporal trends in the time series of the multiscalar drought indices. The test statistic $Z_{m k}$ is calculated as (Mann, 1945; Kendall, 1975)

$Z_{m k}= \begin{cases}\frac{S-1}{\sqrt{\operatorname{Var}(S)}}, & \text { if } S>0 \\ 0, & \text { if } S=0 \\ \frac{S+1}{\sqrt{\operatorname{Var}(S)}}, & \text { if } S<0\end{cases}$

where

$S=\sum_{i=1}^{n-1} \sum_{k=i+1}^{n} \operatorname{sgn}\left(x_{k}-x_{i}\right)$

$\operatorname{Var}(S)=\frac{\left[n(n-1)(2 n+5)-\sum_{i=1}^{m} t_{i}\left(t_{i}-1\right)\left(2 t_{i}+5\right)\right]}{18}$

where $\operatorname{Var}(S)$ is the variance of the statistic $S ; x_{k}$ and $x_{i}$ are the sequential data values; $m$ is the number of tied groups; $t_{i}$ denotes the number of data points in the $i$ th group; $n$ is the length of the data set; and $\operatorname{sgn}\left(x_{k}-x_{i}\right)$ is the sign function, determined as

$\operatorname{sgn}\left(x_{k}-x_{i}\right)= \begin{cases}+1, & \text { if } x_{k}-x_{i}>0 \\ 0, & \text { if } x_{k}-x_{i}=0 \\ -1, & \text { if } x_{k}-x_{i}<0\end{cases}$

Positive values of $Z_{m k}$ indicate increasing trends, while negative values show decreasing trends. In our study, the significance of the trends was tested at the $\alpha=0.05$ significance level. The null hypothesis of no trend is rejected if $\left|Z_{m k}\right|>1.96$.
Hamed and Rao (1998) noted that a significant serial correlation in a time series could lead to a biased estimate of $\operatorname{Var}(S)$. To remove the effect of serial correlation, they recommend using a modified variance $S, \operatorname{Var}^{*}(S)$, in the calculation of $Z_{m k}$. Serial correlation coefficients $\rho_{s}(i)$ at $\operatorname{lag}(i)$ that are significantly different from zero at the $5 \%$ significance level are used to obtain the $\operatorname{Var}^{*}(S)$ as

$\operatorname{Var}^{*}(S)=\operatorname{Var}(S) * \operatorname{Cor}$

where Cor represents a correction due to autocorrelation in the time series data, which is calculated as

Cor $=1+\frac{2}{n(n-1)(n-2)} \sum_{i=1}^{n-1}(n-1)(n-i-1)(n-1-2) \rho_{s}(i)$

Details on the autocorrelation calculation for the determination of significance could be found elsewhere and are not listed here (Box et al., 1994).

\subsubsection{Spatial interpolation}

Spatial interpolation was performed to visualize the spatial patterns of the drought conditions and trends across the region. Here, the ordinary kriging method was used, as it yields higher interpolation accuracy than the other commonly used methods, i.e. inverse distance weighting and splines, indicated by the root mean squared error validated with leave-one-out method. Details on the background theory and calculation steps of kriging interpolation can be found in Goovaerts (1999).

\section{Results}

\subsection{Spatiotemporal variation of climate}

Precipitation and temperature are the core climatic variables in drought studies. Given the regional perspective and relatively long time span of the current study, it is necessary to obtain insight into the spatial and temporal variation of the original climate variables. Descriptive statistics of the monthly precipitation (MP) and mean monthly temperature (MMT) data from January 1957 to December 2012 (56 years) for the 54 selected meteorological stations are listed in Table 1. Among the different stations, the mean values of MP and MMT varied from $12.1 \mathrm{~mm}$ to $68.6 \mathrm{~mm}$ and from $-2.3^{\circ} \mathrm{C}$ to $8.25^{\circ} \mathrm{C}$, respectively. Spatially, the $\mathrm{CV}$ values of the means of the MP and MMT for all 54 stations were $33.5 \%$ and $33.8 \%$, which both indicate moderate variation (Nielsen and Bouma, 1985). At the annual time scale, the mean values of the annual precipitation (AP) and mean annual temperature (MAT) spatially ranged from $143.6 \mathrm{~mm}$ to $824 \mathrm{~mm}$ and from $-2.4^{\circ} \mathrm{C}$ to $14{ }^{\circ} \mathrm{C}$ across the region, respectively. The means of AP and MAT also showed a moderate spatial variation, as indicated by their CV values of $34 \%$ and 35\%, respectively. However, at each station, the MP and MMT presented strong temporal variations over 56 -year span. The CV values of the MP and MMT time series (672 months) for different meteorological stations varied from $92.1 \%$ to $170.5 \%$ and from $68.2 \%$ to $1026 \%$, with mean CV values of $123.1 \%$ and $150 \%$, respectively. However, the mean CV values of the AP and MAT time series (56 years) were $25.6 \%$ and $12.3 \%$, respectively.

The results indicate that temporal variation of monthly climate variables could be much stronger than the spatial variation across the study region. Moreover, the inner-annual variation of precipitation and temperature was much greater than the inter-annual variation over the 56 years. Similar results were also reported by Yao et al. (2013) and B. Zhang et al. (2012) and T. Zhang et al. (2012). It was also demonstrated that the extent of the detected variations largely depend on the chosen temporal or spatial scales 
Table 1

Basic statistics of monthly and annual precipitation and temperature in the selected 54 meteorological stations across the Loess Plateau region.

\begin{tabular}{|c|c|c|c|c|c|c|c|c|c|c|c|c|}
\hline \multirow[t]{3}{*}{ Station } & \multicolumn{6}{|c|}{ Precipitation (mm) } & \multicolumn{6}{|c|}{ Temperature $\left({ }^{\circ} \mathrm{C}\right)$} \\
\hline & \multicolumn{4}{|c|}{ Monthly $(n=672)$} & \multicolumn{2}{|c|}{ Annual $(n=56)$} & \multicolumn{4}{|c|}{ Monthly $(n=672)$} & \multicolumn{2}{|c|}{ Annual $(n=56)$} \\
\hline & Mean & Min & Max & $\mathrm{CV} \%$ & Mean & $\mathrm{CV} \%$ & Mean & Min & Max & $\mathrm{CV} \%$ & Mean & $\mathrm{CV} \%$ \\
\hline LinXia & 42.2 & 0 & 217.1 & 105.4 & 503.9 & 19.5 & 7.1 & -9.1 & 20.8 & 123.3 & 7.1 & 7.6 \\
\hline WuGong & 50.6 & 0 & 416.7 & 107.7 & 607.9 & 26.3 & 13.3 & -4.1 & 28.6 & 70.2 & 13.3 & 4.3 \\
\hline YuZhong & 32.2 & 0 & 207 & 114.3 & 385.8 & 22.0 & 6.8 & -11.1 & 22.1 & 137.3 & 6.8 & 7.7 \\
\hline XiJi & 33.8 & 0 & 226.3 & 115.1 & 404.8 & 22.4 & 5.6 & -12.7 & 20.7 & 167.8 & 5.6 & 11.0 \\
\hline Changwu & 48.4 & 0 & 312 & 104.9 & 581.9 & 22.2 & 9.3 & -8.6 & 24 & 100.7 & 9.3 & 5.5 \\
\hline TianShui & 43.1 & 0 & 217.8 & 100.0 & 516.1 & 23.3 & 11.1 & -4.7 & 26.2 & 78.9 & 11.0 & 5.8 \\
\hline PingLiang & 41.5 & 0 & 317.3 & 116.5 & 497.4 & 22.2 & 9.0 & -8.6 & 23.9 & 100.9 & 9.0 & 7.4 \\
\hline LanZhou & 25.3 & 0 & 236.2 & 123.3 & 304.9 & 26.7 & 9.5 & -11.6 & 26 & 104.9 & 9.5 & 10.1 \\
\hline XiFeng & 45.6 & 0 & 289.1 & 109.0 & 547.0 & 21.3 & 8.8 & -9.2 & 22.9 & 103.8 & 8.8 & 9.5 \\
\hline MinHe & 29.0 & 0 & 198 & 115.6 & 347.0 & 23.6 & 8.1 & -9.4 & 22.9 & 113.0 & 8.1 & 7.1 \\
\hline GuYuan & 37.4 & 0 & 324.4 & 120.7 & 447.8 & 22.7 & 6.6 & -11.6 & 21.8 & 143.1 & 6.6 & 11.8 \\
\hline LuoChuan & 50.9 & 0 & 293.7 & 106.5 & 610.3 & 20.6 & 9.6 & -8.6 & 24.3 & 97.0 & 9.6 & 7.4 \\
\hline WuQi & 38.9 & 0 & 241.2 & 119.6 & 465.8 & 23.5 & 8.0 & -11.7 & 23.6 & 126.8 & 8.0 & 6.9 \\
\hline XiNing & 32.3 & 0 & 175.6 & 109.8 & 385.4 & 19.7 & 6.0 & -11.2 & 19.7 & 147.5 & 5.9 & 8.3 \\
\hline YinChuan & 16.1 & 0 & 148.7 & 141.6 & 191.5 & 32.7 & 9.1 & -14.6 & 25.7 & 121.1 & 9.1 & 8.9 \\
\hline JingYuan & 19.5 & 0 & 162.6 & 123.1 & 233.7 & 26.8 & 9.1 & -10.2 & 25.4 & 112.9 & 9.1 & 6.8 \\
\hline YanAn & 44.5 & 0 & 303.5 & 116.0 & 534.4 & 22.2 & 10.0 & -9.4 & 25.7 & 100.9 & 9.9 & 8.1 \\
\hline JieXiu & 38.4 & 0 & 293.3 & 120.3 & 459.3 & 24.2 & 10.8 & -7.5 & 26.1 & 93.1 & 10.7 & 5.8 \\
\hline YuShe & 45.3 & 0 & 298.6 & 123.0 & 540.9 & 23.4 & 8.9 & -10.4 & 24.1 & 114.5 & 8.9 & 5.1 \\
\hline HuanXian & 35.6 & 0 & 312.6 & 123.8 & 425.1 & 28.0 & 8.8 & -10.1 & 25 & 113.4 & 8.8 & 9.2 \\
\hline TaiYuan & 36.7 & 0 & 360 & 129.7 & 440.3 & 26.6 & 10.1 & -9.2 & 26.4 & 102.7 & 10.0 & 7.6 \\
\hline YangCheng & 50.0 & 0 & 468.6 & 115.1 & 602.3 & 22.5 & 11.9 & -6 & 26.8 & 80.9 & 11.9 & 3.9 \\
\hline $\mathrm{HeQu}$ & 34.2 & 0 & 339.4 & 137.6 & 406.0 & 31.4 & 8.4 & -15.5 & 26 & 142.1 & 8.3 & 8.9 \\
\hline LinFen & 40.1 & 0 & 287.9 & 122.3 & 480.6 & 24.5 & 12.8 & -6 & 28.5 & 80.4 & 12.7 & 5.8 \\
\hline YouYu & 35.1 & 0 & 264.7 & 125.3 & 418.8 & 25.5 & 4.0 & -20.7 & 22.4 & 301.5 & 4.0 & 19.0 \\
\hline WuZhai & 39.1 & 0 & 348.4 & 122.2 & 468.7 & 22.9 & 5.2 & -19.3 & 22.1 & 222.7 & 5.1 & 13.4 \\
\hline Huhhot & 34.2 & 0 & 360.7 & 143.1 & 408.2 & 34.6 & 6.7 & -18.5 & 26.5 & 180.4 & 6.7 & 15.2 \\
\hline YuanPing & 35.5 & 0 & 391.7 & 137.9 & 425.9 & 29.2 & 9.1 & -10.9 & 25.7 & 120.6 & 9.1 & 9.4 \\
\hline XiXian & 43.3 & 0 & 276.1 & 117.8 & 520.1 & 24.2 & 9.3 & -10.7 & 24.6 & 109.2 & 9.3 & 7.2 \\
\hline HaiYuan & 31.7 & 0 & 227.1 & 121.1 & 379.4 & 26.0 & 7.4 & -11.9 & 22.9 & 126.3 & 7.4 & 9.3 \\
\hline YuLin & 33.6 & 0 & 330.2 & 136.2 & 399.5 & 26.5 & 8.4 & -14.4 & 25.7 & 135.1 & 8.4 & 9.2 \\
\hline GuiDe & 21.3 & 0 & 112.1 & 115.9 & 254.0 & 21.7 & 7.4 & -8.6 & 22.3 & 117.3 & 7.4 & 7.1 \\
\hline LiShi & 40.6 & 0 & 304.2 & 124.4 & 485.8 & 25.1 & 9.3 & -11.4 & 26 & 116.2 & 9.2 & 8.1 \\
\hline ZhongNing & 17.0 & 0 & 162.2 & 140.5 & 203.4 & 34.9 & 9.6 & -11.1 & 26.1 & 110.5 & 9.6 & 7.4 \\
\hline TaoLe & 15.1 & 0 & 184.7 & 154.0 & 179.7 & 34.4 & 8.6 & -14.6 & 26.4 & 135.4 & 8.6 & 8.5 \\
\hline YanChi & 24.2 & 0 & 244.1 & 133.1 & 289.4 & 29.8 & 8.2 & -13 & 25.2 & 133.1 & 8.2 & 9.0 \\
\hline DaTong & 31.4 & 0 & 231.8 & 121.9 & 373.8 & 22.8 & 7.0 & -15.4 & 25.8 & 166.4 & 7.0 & 11.1 \\
\hline HengShan & 31.3 & 0 & 208.7 & 127.3 & 373.9 & 25.9 & 8.9 & -12.9 & 25.9 & 124.5 & 8.9 & 6.9 \\
\hline YunCheng & 44.4 & 0 & 287.4 & 110.4 & 535.0 & 22.9 & 14.0 & -4.6 & 29.9 & 72.5 & 14.0 & 4.5 \\
\hline XingXian & 40.5 & 0 & 349.3 & 122.7 & 484.8 & 26.8 & 8.9 & -13.5 & 26.1 & 127.2 & 8.8 & 8.5 \\
\hline BaoTou & 25.7 & 0 & 229.2 & 143.8 & 305.6 & 33.1 & 7.2 & -19.1 & 27.6 & 169.3 & 7.2 & 12.9 \\
\hline SuiDe & 37.1 & 0 & 307.4 & 124.7 & 445.8 & 22.9 & 9.9 & -11.5 & 26.6 & 111.0 & 9.9 & 5.9 \\
\hline HuiNong & 14.6 & 0 & 183.7 & 162.2 & 174.7 & 38.3 & 8.9 & -12.9 & 26.4 & 128.5 & 8.8 & 9.0 \\
\hline TongXin & 22.2 & 0 & 207.1 & 125.7 & 266.0 & 30.7 & 9.0 & -11.7 & 25.9 & 118.1 & 9.0 & 8.6 \\
\hline DongSheng & 32.0 & 0 & 243.2 & 136.8 & 379.5 & 28.9 & 6.2 & -17.5 & 24.6 & 181.6 & 6.2 & 15.5 \\
\hline LinHe & 12.1 & 0 & 193.6 & 170.5 & 143.6 & 37.1 & 7.9 & -20.1 & 26.9 & 154.0 & 7.9 & 15.3 \\
\hline JingTai & 15.3 & 0 & 113.8 & 131.9 & 183.9 & 30.2 & 8.7 & -11.3 & 25.1 & 117.2 & 8.7 & 8.5 \\
\hline ETuoKeQi & 22.3 & 0 & 354.6 & 154.9 & 266.8 & 36.4 & 7.1 & -17.8 & 25.1 & 163.5 & 7.1 & 11.9 \\
\hline WuTaiShan & 64.2 & 0 & 403.1 & 108.0 & 770.5 & 28.1 & -2.3 & -22.9 & 17 & 440.9 & -2.4 & 113.0 \\
\hline MenYuan & 43.8 & 0 & 208.6 & 100.5 & 525.5 & 12.5 & 0.9 & -18.5 & 14.9 & 1026.6 & 0.8 & 90.6 \\
\hline LinTao & 44.1 & 0 & 355.6 & 105.9 & 526.8 & 20.8 & 7.3 & -10.8 & 22 & 121.4 & 7.3 & 7.2 \\
\hline HuaJiaNing & 40.3 & 0 & 333 & 105.0 & 482.8 & 21.6 & 3.7 & -13.5 & 17.3 & 222.0 & 3.7 & 15.6 \\
\hline HuaShan & 68.6 & 0 & 369.5 & 92.1 & 824.0 & 20.7 & 6.2 & -10.8 & 19.4 & 134.3 & 6.2 & 10.1 \\
\hline SanMenXia & 46.4 & 0 & 328.7 & 110.6 & 555.2 & 22.6 & 14.0 & -3.5 & 29.2 & 68.2 & 14.0 & 3.7 \\
\hline
\end{tabular}

(Western and Blöschl, 1999; Vicente-Serrano et al., 2010). Therefore, the interpretation and conclusions of regional drought studies should be closely related to certain spatial and temporal scales.

\subsection{PCA on SPI and SPEI time series}

Multiscalar drought indices, the SPI and SPEI, were calculated for the 54 meteorological stations to monitor the regional drought conditions over 672 months from 1954 to 2012. The results of PCA performed on the SPI and SPEI time series on a 12-month time scale (SPI-12 and SPEI-12) are shown in Table 2. For the SPI-12 time series, the percentages of the variance explained by the first four un-rotated PCs were $42.36 \%, 10.90 \%, 5.84 \%$ and $4.80 \%$, respec- tively, for a cumulative variance of $63.90 \%$. For the SPEI-12 time series, the first four un-rotated PCs explained 46.38\%, 9.36\%, 8.03 and $5.61 \%$ of the total variance, respectively, for a cumulative variance of $69.38 \%$. After the variance maximum rotation, the total variance was evenly explained by the four rotated principal components (RPCs), while the cumulative variance was unchanged with respect to the un-rotated case.

The rotated loadings of the leading four PCs for SPI-12 and SPEI12 were calculated for each meteorological station. As shown in Fig. 2, the rotated loadings were interpolated based on the coordinates of the 54 meteorological stations to cover the entire region. For SPI-12, the high positive loadings in the first RPC (RPC1) were located in the east of the region, with a maximum loading value of 
Table 2

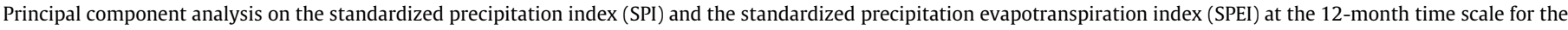
54 meteorological stations across the Loess Plateau region.

\begin{tabular}{|c|c|c|c|c|c|c|}
\hline \multirow[t]{2}{*}{ Principal component } & \multicolumn{3}{|l|}{ SPI-12 } & \multicolumn{3}{|l|}{ SPEI-12 } \\
\hline & Eigenvalue & Explained variance-unrot. & Explained variance-rot. & Eigenvalue & Explained variance-unrot. & Explained variance-rot. \\
\hline PC1 & 23.30 & 42.36 & 16.23 & 25.51 & 46.38 & 17.54 \\
\hline PC2 & 5.99 & 10.90 & 16.20 & 5.15 & 9.36 & 17.51 \\
\hline PC3 & 3.21 & 5.84 & 15.94 & 4.42 & 8.03 & 17.27 \\
\hline PC4 & 2.64 & 4.80 & 15.53 & 3.08 & 5.61 & 17.06 \\
\hline Cumulative variance & & 63.90 & 63.90 & & 69.38 & 69.38 \\
\hline
\end{tabular}

0.83 in JieXiu (Fig. 2a). This indicated that the east part of the region had a similar temporal variation of drought conditions detected by SPI at the 12-month time scale. Similarly, the high positive rotated loadings in RPC2, RPC3 and RPC4 of SPI-12 were located in the northwest, west and northeast parts of the region, with maximum loading values in HuiNong, TongXin and WuZhai, respectively (Fig. 2b-d). However, when considering the temperature and potential evapotranspiration, the spatial pattern of drought conditions captured by SPEI at the 12-month time scale was not the same as that captured by SPI. Approximately $70 \%$ of the temporal variation of the SPEI-12 time series across the region was extracted by the leading four RPCs (Table 2). As shown in Fig. 2e-h, the four RPCs could represent the common temporal drought behaviors of the southwest, southeast, northeast and east parts of the study region, respectively. The maximum values of the rotated loadings in each RPC were located in LanZhou (0.87), WuGong (0.89), YouYu (0.82) and XiXian (0.81), respectively. Although the four leading RPCs could not fully extract the temporal variance of SPI-12 and SPEI-12, their loadings seem to well separate the study region into four distinct sub-regions, characterized by different drought variabilities. This should be attributed to the different precipitation and temperature regimes within the region, which were also affected by the varied local topography and landscape (Wang et al., 2011; Jiang et al., 2014).

The corresponding rotated PC score time series were also obtained for SPI-12 and SPEI-12 at each meteorological station. As plotted in Fig. 3, the scores of the four RPCs and the original drought indices (SPI-12 and SPEI-12) at the corresponding representative stations showed very similar temporal behaviors. Multi-year fluctuations were evident with different temporal patterns and trends among different areas. Moreover, remarkable drought events were expected to occur in different years. As monitored by SPI-12, extreme drought events would occur in 1958, 1966, 1998 and 2000 in the east area represented by RPC1 (Fig. 3a), while extreme drought events would occur in 1966, 1972, 2006 and 2009 and 1963, 1964, 1972, 1986, 1994 and 2000 in the northeast (RPC2) and northwest (RPC4) areas, respectively (Fig. 3b and d). Using SPEI-12, extreme drought events were expected to occur frequently after 2003 in the southwest area represented by RPC1 (Fig. 3e). As captured by RPC2, extreme drought events occurred in 1960, 1978, 1995, 1996 and 1998 in the south area, while no drought events were detected after 2003 (Fig. 3f). As for the RPC3 of SPEI-12 in the northeast area, extreme drought events happened more frequently, in 1963, 1964, 1973, 1977, 1987 and 2000 (Fig. 3g). Moreover, the RPC1 of SPEI-12 showed an apparent decreasing trend from 1994 to 2012 (Fig. 3e), whereas a remarkable increasing trend was found for the RPC2 of SPEI-12 during the same period (Fig. 3f).

\subsection{Spatial patterns of temporal trends of drought}

The autocorrelation functions of the SPI-12 and SPEI-12 time series were plotted for these representative meteorological stations, determined by PCA (Fig. 4). The results indicate that both the SPI-12 and SPEI-12 time series showed strong serial correlations, being positively and significantly autocorrelated up to a time lag of approximately 10 months. However, the autocorrelation coefficients decreased rapidly from time lag 1 to time lag 12 . This should be related to the inherent calculations of SPI-12 and SPEI-12 by using the 12-month time scale. The maximum time lags for significant autocorrelation slightly differed among the different meteorological stations. For example, the SPI-12 time series was significantly autocorrelated up to 9-month lags in JieXiu, while the autocorrelation became weak and not significant after 11 months in HuiNong. Similarly, the SPEI-12 time series were significantly autocorrelated up to 9 months and 10 months for YouYu and XiXian, respectively. Notably, the serial correlations were all significant and positive within the 9-month lags for the 54 meteorological stations across the Loess Plateau. In Serbia, Gocic and Trajkovic (2013) found that only 5 out of 12 meteorological stations showed a positive serial correlation of the SPI-12 time series at a time lag of 1 month. Moreover, their results indicated that it was important to remove the positive serial correlation of SPI-12 to obtain reliable results of the temporal trend using the MannKendall test.

The spatial distribution of the temporal trend statistic $Z_{m k}$ and modified $Z_{m k}\left(M Z_{m k}\right)$ of the SPI-12 and SPEI-12 time series were interpolated for the entire study region in Fig. 5. Before removing the serial correlation, more than $90 \%$ of the area of the region had negative $Z_{m k}$ values of SPI-12 less than -1.96 , except for two areas in the north (HeTao Plain) and west of the region (to the south of QiLian Mountain and WuQiao Mountain) (Fig. 5a). This indicates that the SPI-12 time series showed a significant decreasing trend, and thus the drought severity represented a significant increasing trend for nearly the entire region. Generally, the intensity of the drought increase was reduced moving from southeast to northwest, in accordance with the distribution patterns of precipitation (Wang et al., 2011). The stronger increase was found in the central part of the region, including 26 meteorological stations located in the east of GanSu province (LanZhou, YuZhong, LinTao, HuiNing, HuaJiaNing, HuanXian, TianShui), south of NingXia province (XiJi, GuYuan, HaiYuan), north of Shaanxi province (WuQi, YanAn, SuiDe), south and west of ShanXi province (WuTaiShan, YuanPing, YangQuan, TaiYuan, JieXiu, YuShe, LiShi, XiXian, LinFen, HouMa, YangCheng, ChangZhi, JinDongNan), and west of HeNan province (LuoYang) (Figs. 5a and 1). However, as shown in Fig. $5 \mathrm{~b}$, the values of $M Z_{m k}$ became much larger than $Z_{m k}$ after removing the serial correlation of the SPI-12 time series. Most areas of the region had negative $M Z_{m k}$ values, but not significantly different from 0 at the $95 \%$ confidence level. Consequently, only three patches showed significant increasing trends of drought severity, including 14 meteorological stations located in GanSu province (YuZhong, HuiNingHuaJiaNing), NingXia province (Xiji, GuYuan), ShaanXi province (YanAn, SuiDe), and ShanXi province (WuTaiShan, YangQuan, ChangZhi, JinDongNan, XiXian, LinFen, YangCheng) (Fig. 5b).

The results of the Mann-Kendall test on the SPEI-12 time series are shown in Fig. 5c and d. Before removing the serial correlation, 

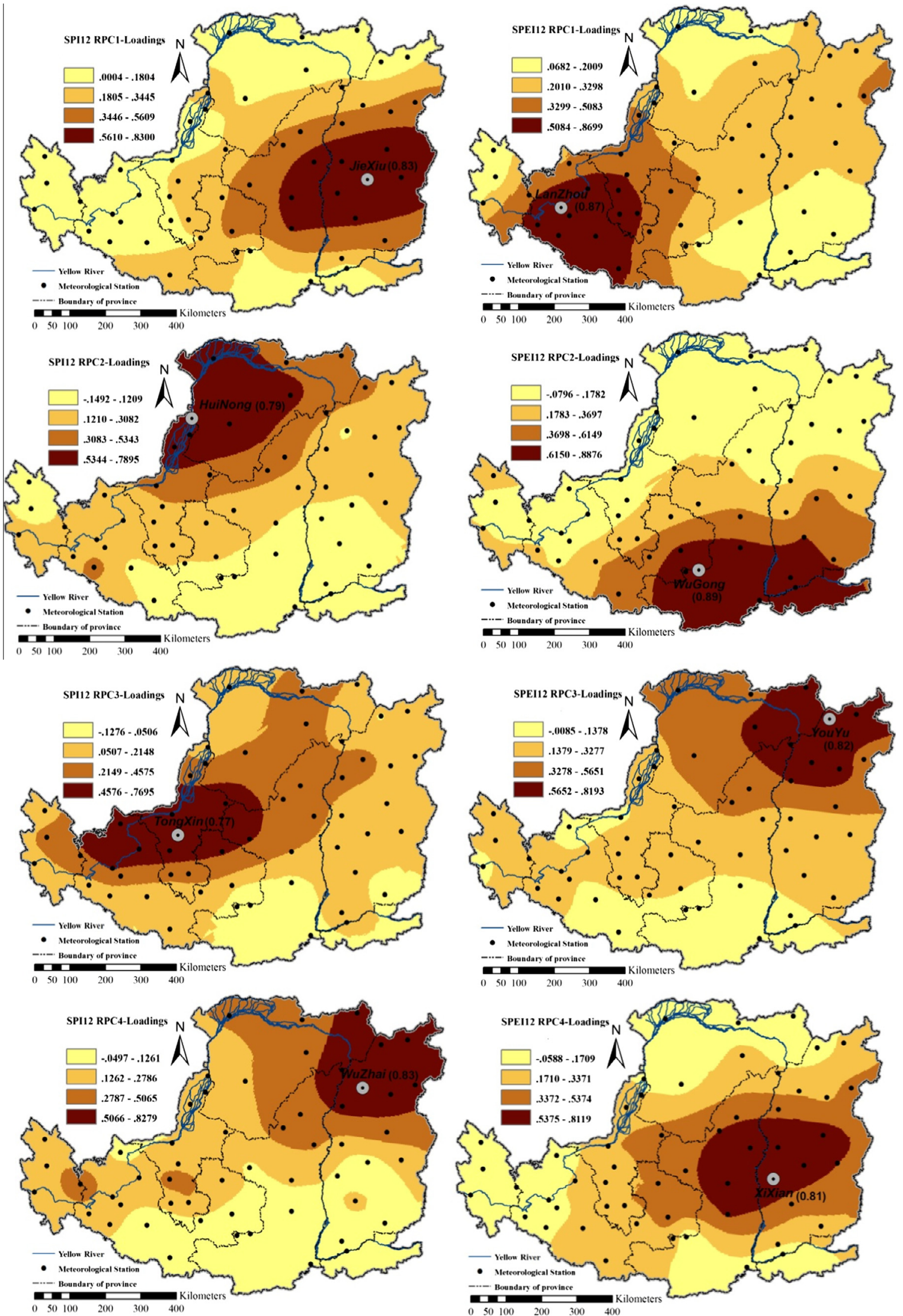

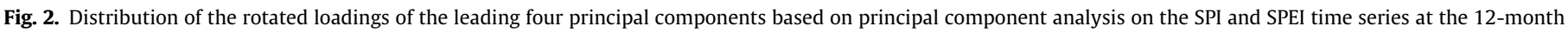
time scale. 

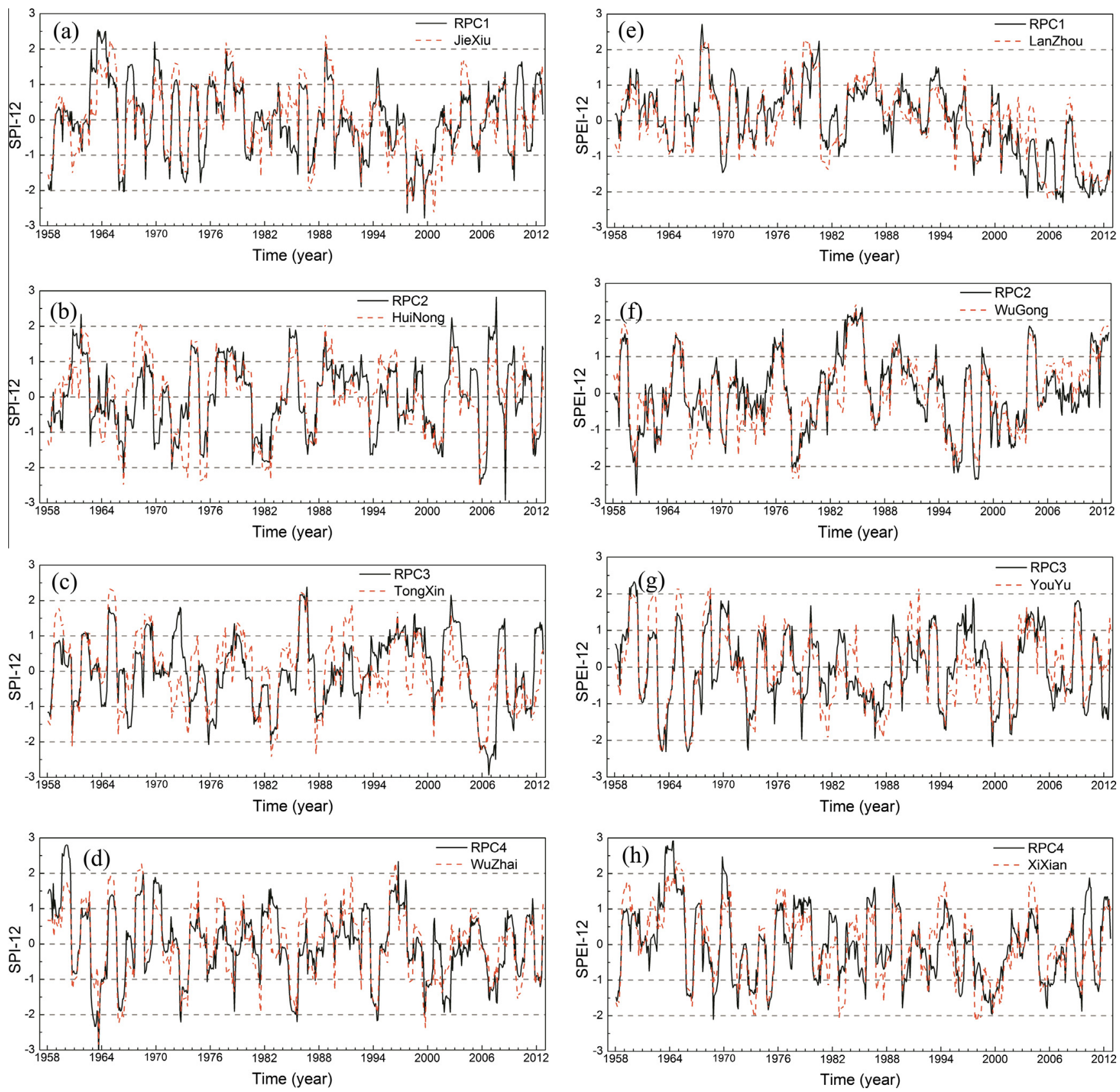

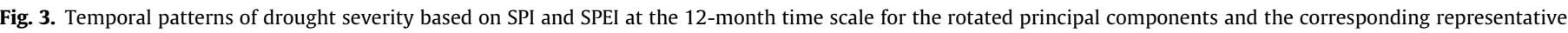
meteorological stations.

about half of the area in the center of the region showed significant increasing trends of drought severity, traversing the region as a belt from southwest to northeast (Fig. 5c). The two patches with the most intensive increasing trends of drought were located in the southwest (TianShui, HuajiaNing, LinTao, HuiNing, YuZhong, Xiji, GuYuan) and northeast (WuTaiShan) of the region. Unlike the results of SPI-12, the two areas in the north (HeTaoPlain) and west of the region had significant positive $Z_{m k}$ values for the SPEI-12 time series, indicating a decreasing trend of drought. However, after removing the serial correlation, the negative $M Z_{m k}$ values became larger and the positive $M Z_{m k}$ values became smaller compared with the $Z_{m k}$ values of the SPEI-12 time series (Fig. 5c and d). Consequently, as illustrated in Fig. 5d, the areas with significant increasing trends of drought severity shrank to a small patch in the southwest of the region, including only four meteorological stations (HuaJiaNing, HuiNing, Xiji, TianShui). Moreover, the decreasing trend of drought severity, detected by the $Z_{m k}$ of the SPEI time series in the north and west of the region, was no longer significant.

\subsection{Spatiotemporal characteristics of drought frequency}

The drought severity was classified into four different categories, i.e., mild drought, moderate drought, severe drought, and extreme drought, according to the values of SPI and SPEI. The drought frequency of each month was calculated for these four drought severities based on SPI and SPEI at 1-, 3-, 6-, 12-, 24-month time scales. As shown in Fig. 6, the monthly drought frequency at various time scales showed different temporal behaviors from January to December. Generally, the drought frequency at 

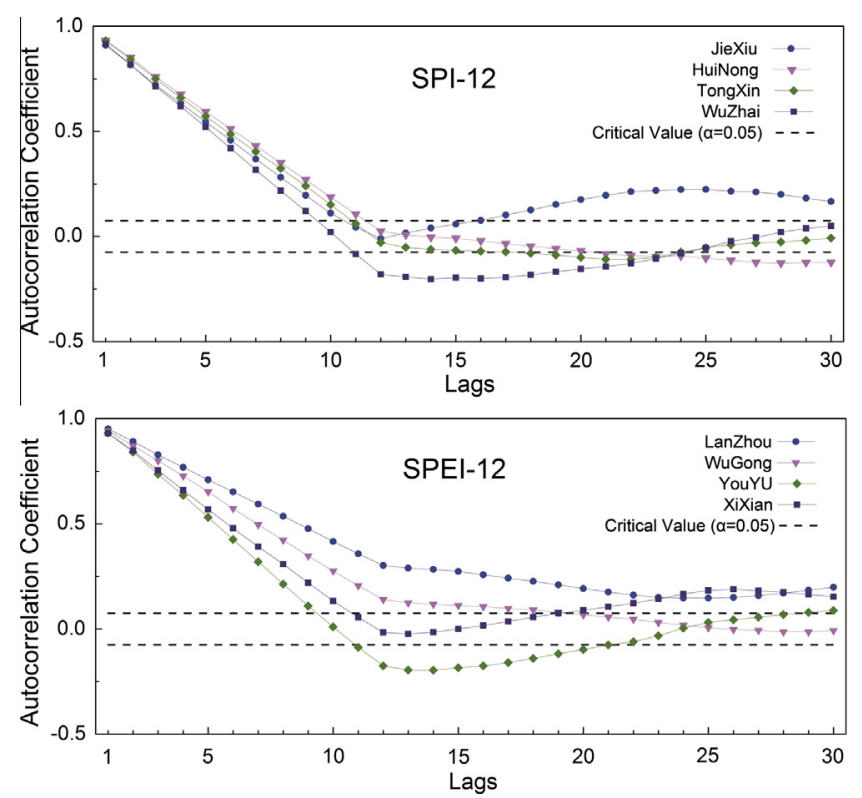

Fig. 4. Autocorrelation functions of the SPI and SPEI time series at the 12-month time scale for the corresponding representative meteorological stations. short time scales (1, 3, 6 months) had greater fluctuations than that at relatively long time scales (12 and 24 months). According to SPI at the 1-month time scale, the mild drought frequency was higher from November to February and lower in May, August and October. However, for moderate, severe and extreme droughts, the frequencies were lower from November to February and higher in May, September and October. According to SPI-3, the mild drought frequency was higher in January, May, July and December, while lower in February. The moderate drought frequency was higher in April and November and lower in January. Severe and extreme drought events seemed to more frequently occur in February and May. According to SPI-6, the mild and moderate drought frequencies were higher in February and April, while the severe and extreme drought frequencies were higher in January. The drought frequencies of SPI at long time scales, i.e., 12- and 24-month time scales, had similar temporal behaviors, with much weaker fluctuations than that at the short time scales. Notably, the extreme drought frequencies of SPI-12 and SPI-24 showed stronger variations than the frequencies of mild drought, moderate drought and severe drought within a year, being apparently higher in July and August. The monthly drought frequencies based on SPI were largely determined by the temporal variation of precipitation, as the SPI calculation only depends on the precipitation data. However, the results also reflected the different behaviors of the various (a)

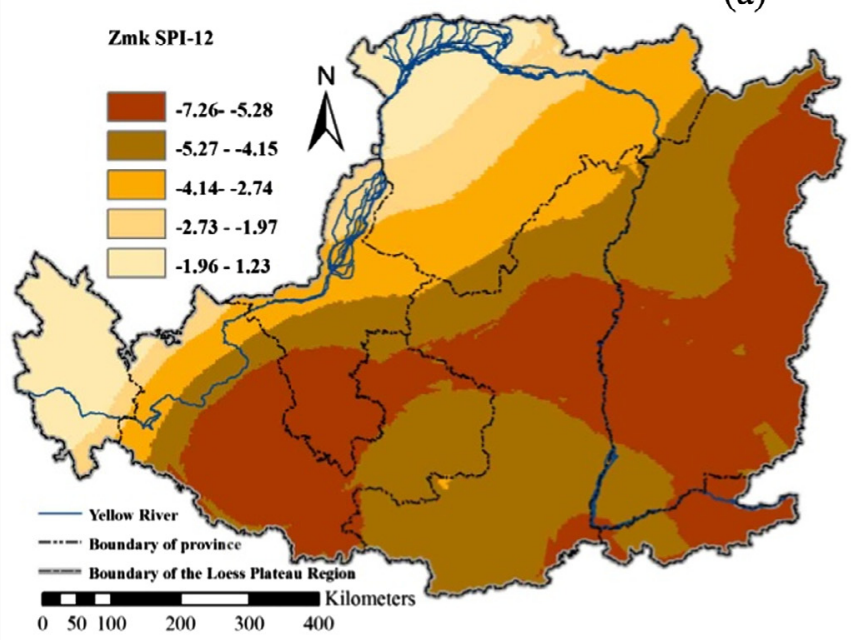

(c)

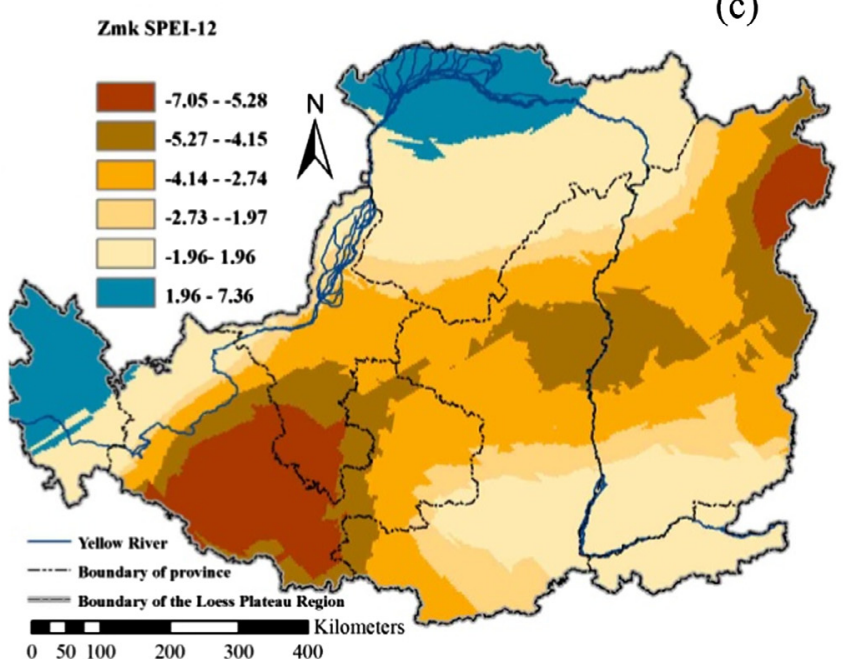

(d)
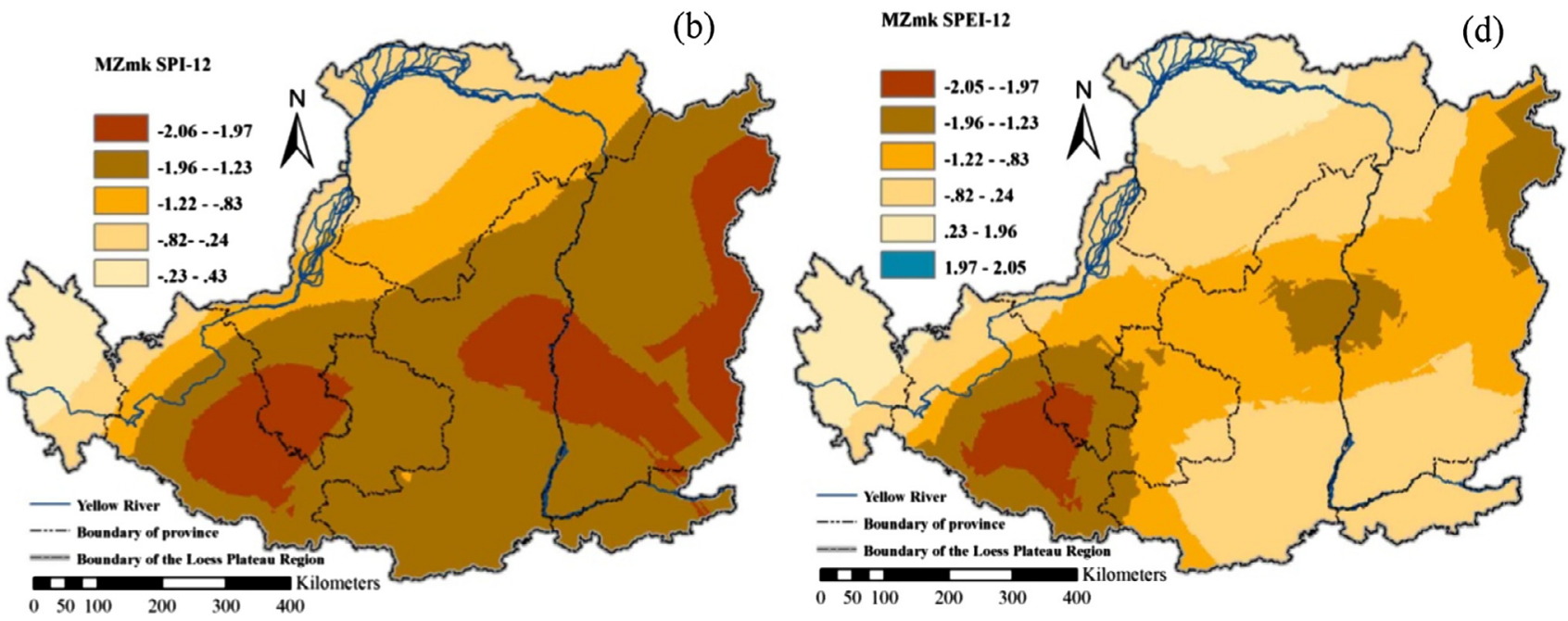

Fig. 5. Spatial patterns of the changing trend of drought severity based on the SPI and SPEI time series at the 12-month time scale detected by Mann-Kendall test. 

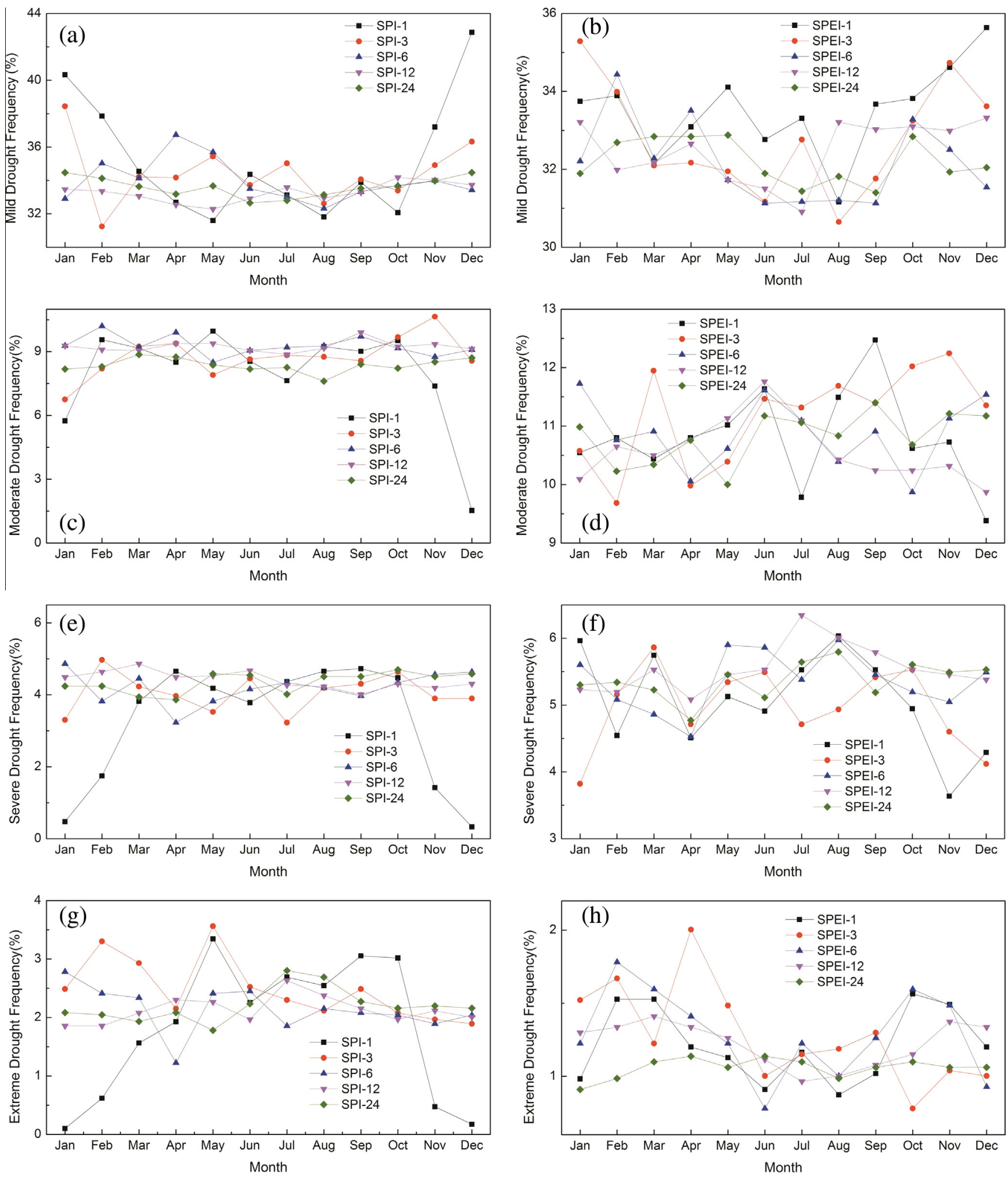

Fig. 6. Drought frequency of different levels of drought severity based the SPI and SPEI at different time scales.

available water pools as responses to abnormal precipitation, which were distinguished by SPI using different time scales (McKee et al., 1993; Vicente-Serrano et al., 2010).

As shown in Fig. 6b, d, f and h, the drought frequencies of different severities monitored by SPEI at various time scales also differed from each other. According to SPEI at the 1-month time scale, the mild drought frequency was higher from November to February and lower in March and August. However, for moderate drought and severe drought, the frequencies were relatively lower in November and December and higher in August and September. Extreme drought events at the 1-month time scale more frequently occurred in February, March, October and November. According to SPEI-3, the mild drought frequency was also higher from November to February, while lower in July and August. The moderate 
drought frequency of SPEI-3 was much higher in November and March, while lower in February. The severe and extreme drought events seemed to more frequently occur in the spring (March and April). According to SPEI-6, the frequencies of moderate and severe droughts were higher in January, May and June, while the mild and extreme drought frequencies were higher in February and lower in June. The drought frequencies of SPEI at long time scales, i.e., 12- and 24-month, also exhibited weaker fluctuations than that of SPEI at short time scales, but still much stronger than that of SPI at long time scales. Generally, for the long-scale droughts monitored by SPEI, the mild and extreme drought frequencies were higher in the winter and spring, whereas the moderate and severe drought frequencies were much higher in the summer. It is clear that the drought frequencies monitored by SPEI showed different temporal patterns and much greater variations over the 12 months than those monitored by SPI. This should be attributed to the inclusion of the effects of temperature in drought monitoring by SPEI (Vicente-Serrano et al., 2010). The temporal variation of both the precipitation and temperature may have synergistic effects on the temporal behavior of the drought conditions.

Given that droughts vary time and space, the regional distribution of the frequency for drought events with SPEI-12 values less than -1.0 was plotted for each of the 12 months in a year (Fig. 7). Clearly, the drought frequency and the dominant areas showed remarkable monthly variation. In January, the area with the highest drought frequency was located in the middle west of the region, mainly in the north of Shaanxi and NingXia provinces and the south of NeiMengGu province. Generally, the drought frequency decreased from southeast to northwest. Similar regional distribution patterns of drought frequency were reported by $B$. Zhang et al. (2012), as detected by the modified PSDI and SPI at the 3-month time scale. However, as illustrated in Fig. 7, the drought frequency showed remarkable spatial and temporal variation across the Loess Plateau region. Clearly, the drought events were expected to occur more frequently in the middle of the winter (January), late spring (May) and early summer (June and July), while the drought-hit areas also changed with time. In January, the areas with higher drought frequencies were mainly located in the south of NeiMengGu province and the north of Shaanxi and NingXia provinces. In May, the drought-hit area expanded to cover almost the whole middle and southern parts of the Loess Plateau, including the north of NingXia province, the east of GanSu province, most areas of ShaanXi province, and the middle of ShanXi province. Afterwards, the area with a higher drought frequency moved to the north of the region in June and July and then shrank rapidly to the northwest boundary of the region in August and September. In the cold November and December, drought events did not generally occur across the entire region.

\section{Discussion}

It has been demonstrated that climate change could lead to remarkable changes in the frequency, intensity, duration and spatial dimensions of climatic extremes and climate events (Zou et al., 2005; IPCC, 2012). Globally, the average surface temperature has significantly increased at a rate of $0.13 \pm 0.03{ }^{\circ} \mathrm{C}$ per decade in the last half century, from 1956 to 2005 (Solomon et al., 2007; Jiang et al., 2014). Meanwhile, the changes in precipitation showed more complicated spatial and temporal patterns in different climatic regions (Dai et al., 1998; Chen et al., 2011). In China, studies found that the area of increasing wetness was larger than the area of increasing dryness (Shen et al., 2009). Shi (2003) noted that the climate in northwest China would experience a change from warming-drying to warming-wetting, which has been demonstrated by studies from Xinjiang and Tibet in China (Du et al.,
2009; Jiang et al., 2009). However, in the eastern part of northwest China, the Loess Plateau region has experienced a warming-drying climatic tendency with increasing temperature and declining precipitation (Ma, 2005; Wang et al., 2011; Yao et al., 2013; Jiang et al., 2014). As a result, the drought severity and frequency was reported to have an overall increasing trend across the Loess Plateau, as detected by various drought indices (B. Zhang et al., 2012; T. Zhang et al., 2012; Yao et al., 2013; Zhao and Wu, 2013; Jiang et al., 2014). However, as influenced by the complex interior topography and landscapes, the precipitation and temperature exhibit high spatial and temporal variabilities across the region (Table 1), which could lead to different responses of drought behaviors. Obviously, it is necessary to take into consideration both the climate change and its spatiotemporal variations when conducting regional drought monitoring and assessment on the Loess Plateau. This requires a robust drought index, which should be temporally and spatially invariant to allow for comparison of the drought severity through time and space and be sensitive to changes in climatic variables. Furthermore, as emphasized by Guttman (1999) and Vicente-Serrano et al. (2010), an effective drought index should have the ability to recognize different types of drought that are closely related to different time scales and various usable water sources. Therefore, two multiscalar drought indices, the SPI and SPEI, were chosen in our study to reveal the spatiotemporal characteristics of drought conditions on the Loess Plateau.

Both of the indices have the capacity to identify the intensification or relief of drought severity related to temporal changes of precipitation at different time scales. Vicente-Serrano et al. (2010) found little difference between the values of the SPI and SPEI in the climatic regions with low temporal variability in temperature. However, as elucidated by the results of the PCA analysis, the spatial patterns of the drought conditions and the representative meteorological stations for drought monitoring were much different when extracting the information from the SPI and SPEI (Table 2 and Fig. 2). Moreover, when including the effects of temperature variability on drought, the spatial patterns of the temporal trends of drought severity based on the SPEI time series were much different than those based on the SPI time series (Fig. 5). This demonstrates that the variability of the temperature would have a remarked impact on the drought severity on the Loess Plateau during the time span from 1954 to 2012. Hu and Willson (2000) also found that temperature anomalies play a crucial role in explaining the drought variability in central United States, and it could be comparable to the role of precipitation under some circumstances. The effects of temperature on drought severity should be attributed to its direct impact on evapotranspiration (Sheffield and Wood, 2008) and the follow-up impacts on runoff, river discharge, groundwater and reservoir water storage (Zipper and Loheide II, 2014). Compared with humid regions in the tropics, evapotranspiration in arid and semiarid regions may play a more influential role in the land surface water balance with respect to the already limited available water resources (Syed et al., 2008). On the Loess Plateau, the average annual evapotranspiration was estimated to be $1060.3 \mathrm{~mm}$, ranging from $865.1 \mathrm{~mm}$ to $1274.0 \mathrm{~mm}$, which was much higher than the average annual precipitation (He et al., 2003; Li et al., 2012). Moreover, the reference evapotranspiration was reported to have a continuous increasing trend in the 21 st century due to the changes in relative humidity and temperature (Li et al., 2012). Given that water shortage is the main constraining factor for agricultural production and ecosystem functions in this region, it is of great necessity to pay more attention to the water losses through evapotranspiration in drought monitoring and analysis, especially in the context of global warming.

It has been generally accepted that the increasing temperature could intensify drought severity by increasing water loss through evapotranspiration. In the SPEI calculation, a decreasing monthly 

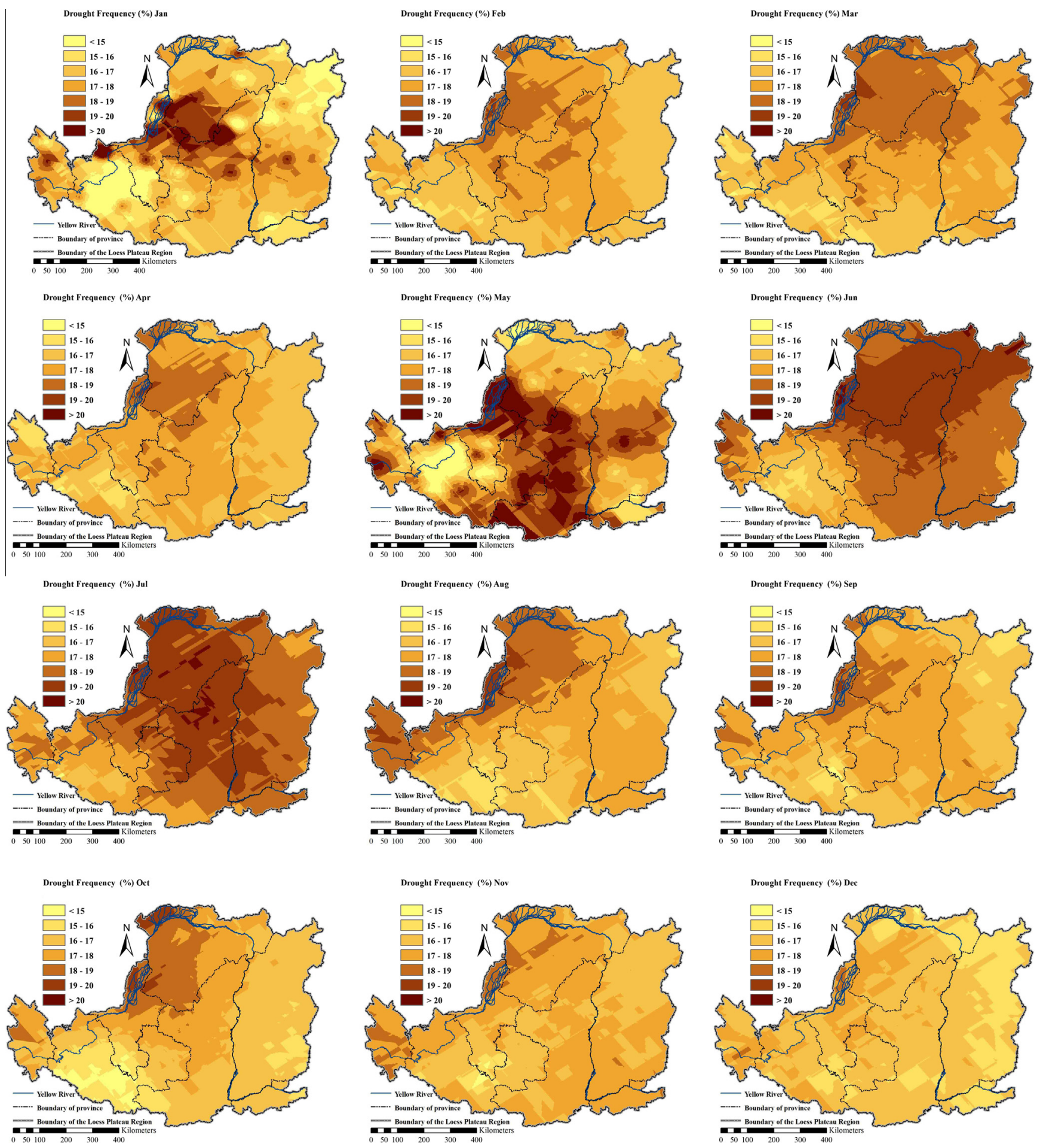

Fig. 7. Drought frequency of the SPEI-12 (value <-1.0) for each month across the Loess Plateau region based on the climate data from 1957 to 2012.

precipitation time series minus an increasing monthly evapotranspiration time series was supposed to yield a water balance D time series (precipitation minus evapotranspiration) with a more intensive decreasing trend. However, our results seem to contradict this speculation. As shown in Fig. 5, the areas with significant increasing trends of drought severity based on the SPEI time series were much smaller than those based on SPI time series. Moreover, the increasing trend of drought severity turned to a decreasing trend in some areas after considering the effects of the elevated temperature on drought conditions. One possible explanation could be that the fluctuations with ups and downs containing in the overall increasing trend of evapotranspiration and decreasing trend of precipitation were not synchronized in time. This would change the probability distribution of the water balance $D$ time series and may yield a relatively weaker decreasing trend of the SPEI time series. Nevertheless, the mechanism of the effects of temperature/eva 
potranspiration on drought severity is more complicated and how the evapotranspiration affect different usable water resources at different time scales are not well understood so far (VicenteSerrano et al., 2010).

To obtain deep insight into the multiscalar drought characteristics on the Loess Plateau, the SPI and SPEI at various time scales $(1,3,6,12$ and 24 months) and the sc-PDSI were plotted together in Figs. 8 and 9 for the two representative meteorological stations, LanZhou and WuGong, determined by PCA analysis (Table 2 and Fig. 2).

According to the sc-PDSI at LanZhou station, the extreme drought events (sc-PDSI $\leqslant-4.0$ ) occurred regularly at an interval of approximately 2-3 years, without much variation in the drought frequency and severity, except for an apparent intensification of drought severity from 1986 to 1999 (Fig. 8). The sc-PDSI time series indicated that the most intensive drought events were supposed to occur in 1990 and 1995 . However, the 1990 drought event was hardly detected by the SPI and SPEI at all time scales (Fig. 8), while the 1995 drought event could be clearly identified by SPI and SPEI at the 3- and 6-month time scales but not at the $1-, 12$ - and 24-month time scales. As shown by the SPI and SPEI time series at LanZhou station (Fig. 8), there was a remarked contrast between a wet episode from 1976 to 1979 and a drought episode from 1980 to 1982 , especially at long time scales. This should be closely related to the abnormal high and low precipitations during these two periods (Fig. 10). However, these two contrasting periods were not evidently identified by the sc-PDSI time series. This may indicate that the SPI and SPEI were more sensitive to the variation of precipitation than the sc-PDSI (Guttman, 1999; Vicente-Serrano et al., 2010). Moreover, a reinforcement of the drought frequency and severity was evidently indicated by the SPI and SPEI after 2004, while it was hardly identified by the sc-PDSI. This reinforcement could be explained by the low precipitation and high temperature after 2004 (Fig. 10). Moreover, the reinforcement of the drought severity was more evident in the SPEI time series than that in the SPI time series at the 1-, 3-, 6- and 12-month time scales. For example, the number of identified extreme drought events after 2004 was 5 times more in the SPEI time series (10 events) than that in the SPI time series (2 events) at the 1 month time scale. This also demonstrates the ability of the SPEI to reflect the effects of temperature on drought severity.

At WuGong station, the sc-PDSI time series was much different from that at LanZhou station, but it also showed a regular occurrence of extreme drought events at an interval of approximately 5 years from 1958 to 1988 (Fig. 9). An extreme drought event was expected to occur in 1977 because the precipitation was abnormally low and the temperature was high in that year. This drought event was accurately identified by the sc-PDSI, as well as by the SPI and SPEI at all time scales. However, the drought duration identified by the SPI and SPEI was much longer at the 12- and 24-month time scales compared with that indicated by the sc-PDSI. Furthermore, an evident intensification of the drought frequency and severity was found by the sc-PDSI from 1995 to 2012, with extreme drought events identified in 1995, 1997, 2000, 2004, 2006, 2009 and 2011 (Fig. 9). The remarkable drought events in 1995, 1997 and 2000 were also identified by the SPI and SPEI at different time scales, which should be attributed to the very low precipitation and high temperature from 1995 to 2000, as illustrated in Fig. 10. However, the drought events after 2004 indicated by the sc-PDSI were hardly detected by the SPI and SPEI. Instead of the intensification of drought severity, a clear humidification trend was indicated by the SPI and SPEI after 2004. The humidification trend was considered to be reasonable, as the precipitation was relatively high with an increasing trend and the temperature was moderate after a shape decrease after 2004 at WuGong station (Fig. 10). Moreover, the humidification trend was more intensive as indicated by the SPEI time series than as indicated by the SPI time series. This was also because the SPEI considered the effects of the decreasing trend of temperature on the drought severity, which is not considered by the SPI.

Previous studies concluded that the PDSI may have an inherent time scale of 9-12 months because the highest correlation coefficient coefficients between the PDSI and SPI/SPEI were found at those time scales (McKee et al., 1993; Lloyd-Hughes and Saunders, 2002; Vicente-Serrano et al., 2010; Jiang et al., 2014). However, in our study, the drought characteristics represented by the sc-PDSI time series greatly differed from those of the SPI and SPEI at the 12-month time scale in terms of the number, start time, duration and severity of the identified drought events (Figs. 8 and 9). More similar temporal patterns of drought severity were found between the sc-PDSI and SPI/SPEI at time scales of 3 and 6 months. Apparently, the temporal patterns of drought severity based on the SPI and SPEI also apparently differed with the time scale. As the time scale increases, drought events occurred with lower frequency and severity but longer duration. This could reflect different availabilities of diverse usable water sources under drought conditions, which allows for the monitoring of different drought types. From this point of view, the multiscalar drought information made the SPI and SPEI superior to the time scale fixed sc-PDSI in drought monitoring and analysis. Moreover, the sc-PDSI is based on a complex water balance calculation, which requires many reliable parameters to guarantee its accuracy. For regional studies, the strong spatial variability of the soil parameters and the difficulty in obtaining them would constrain the application and accuracy of the sc-PDSI. In contrast, the SPI and SPEI are preferred to be used given their simple forms and lower data requirements. When comparing the SPI with the SPEI, the SPEI is considered to be superior to the SPI under global warming scenarios because it can identify the role of temperature variation in drought conditions.

Several studies have assessed the potential impacts of climate change on drought behaviors using the SPEI. For example, Vicente-Serrano et al. (2010) compared the original SPEI and the modeled SPEI under a warming scenario, with the addition of progressive temperature increases of $2{ }^{\circ} \mathrm{C}$ and $4{ }^{\circ} \mathrm{C}$ over a nearly 100-year time span. On the Loess Plateau, Jiang et al. (2014) investigated the SPEI time series in a hypothetical scenario of a progressive temperature increase of $2{ }^{\circ} \mathrm{C}$ and a progressive precipitation decrease of $15 \%$ over 61 years from 1951 to 2012. Without dispute, they all concluded that a reinforcement of the drought severity was identified by the SPEI. However, the temporal variations in temperature and precipitation are surely not progressive but rather exhibit great fluctuations. As shown in Fig. 10, although the precipitation and temperature exhibit overall decreasing and increasing trends, respectively, there are also different changing trends during different periods as well as marked abrupt changes associated with extreme climatic events. Using wavelet analysis, Yao et al. (2013) found that the terrestrial annual humidity index had an evident fluctuation period of 3-8 years, changing for different areas on the Loess Plateau. Therefore, the progressive change assumption should be carefully used for future drought assessment to accurately predict drought severity in the future, especially at short time scales. Moreover, the independent changes of precipitation and temperature also neglect the close correlations between them. This may underestimate or overestimate the effects of climate change on drought conditions. Moreover, the changing trends of precipitation and temperature and the possible relationships between them may also vary over space. It is still a great challenge to determine the effects of future fluctuations of climatic variables and their spatially varied relationships on drought conditions. The results of the current study on the spatial and temporal patterns of drought conditions may serve as a 

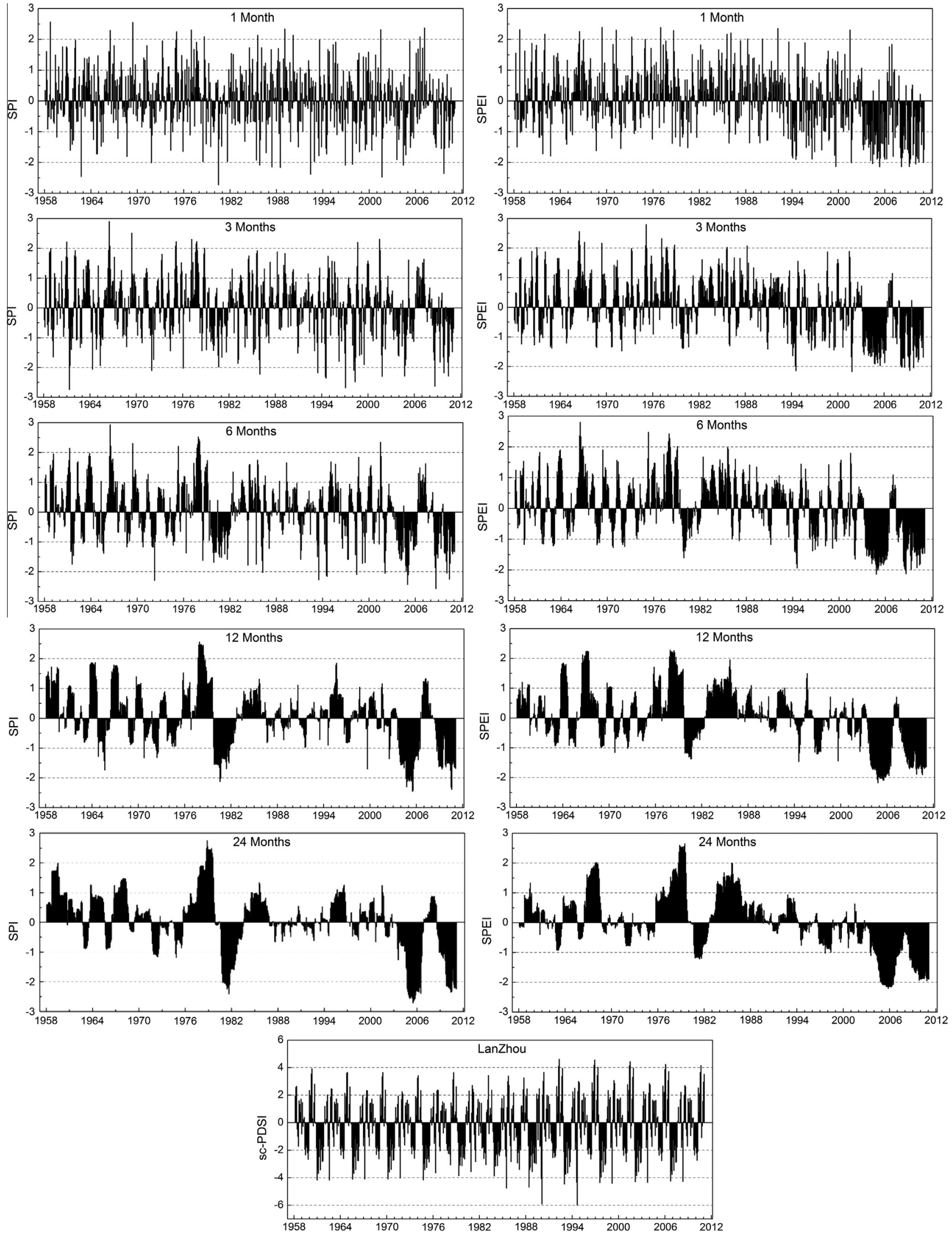

Fig. 8. Temporal patterns of drought severity indentified by the sc-PDSI and SPI and SPEI at different time scales in LanZhou. 

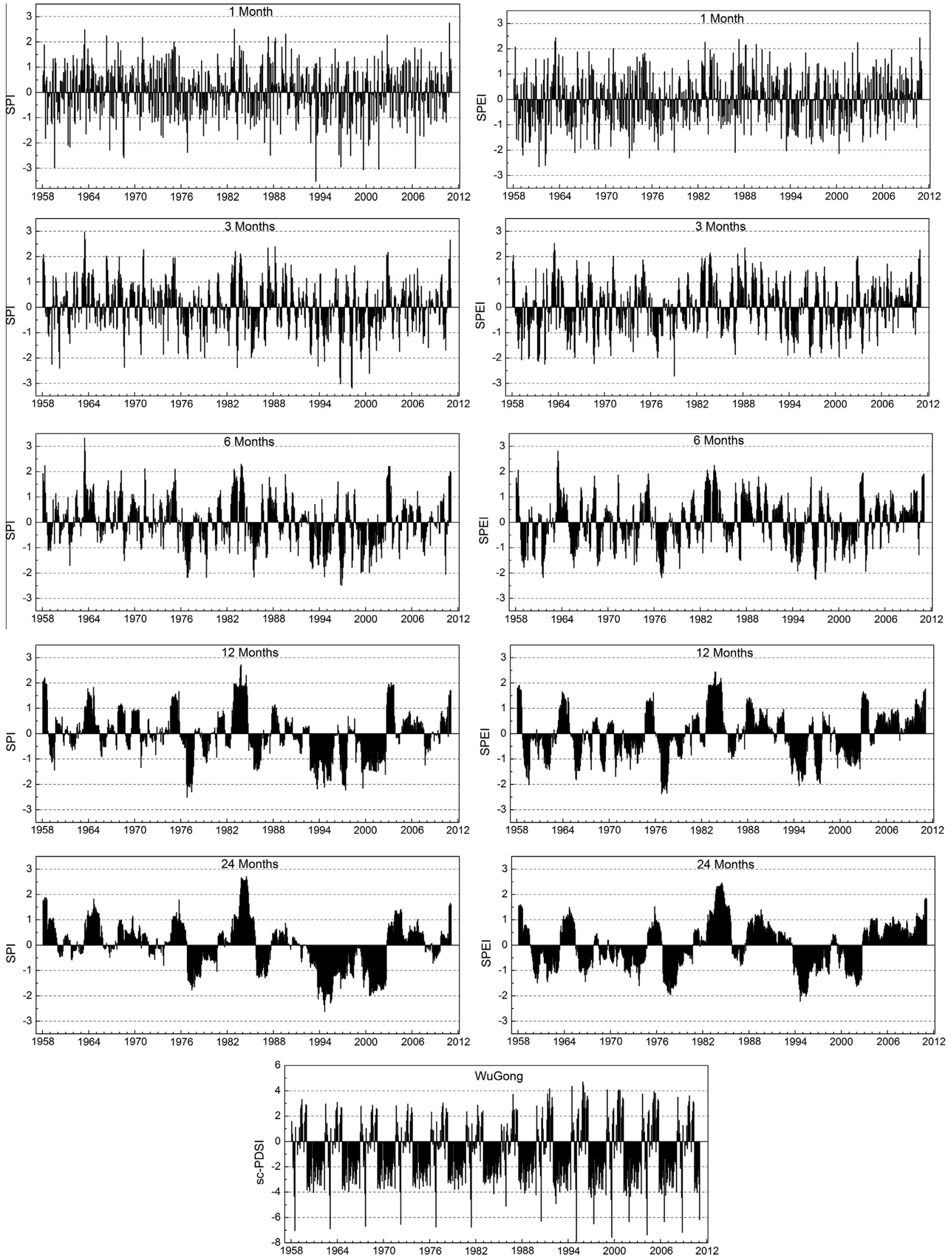

Fig. 9. Temporal patterns of drought severity indentified by the sc-PDSI and SPI and SPEI at different time scales in WuGong. 

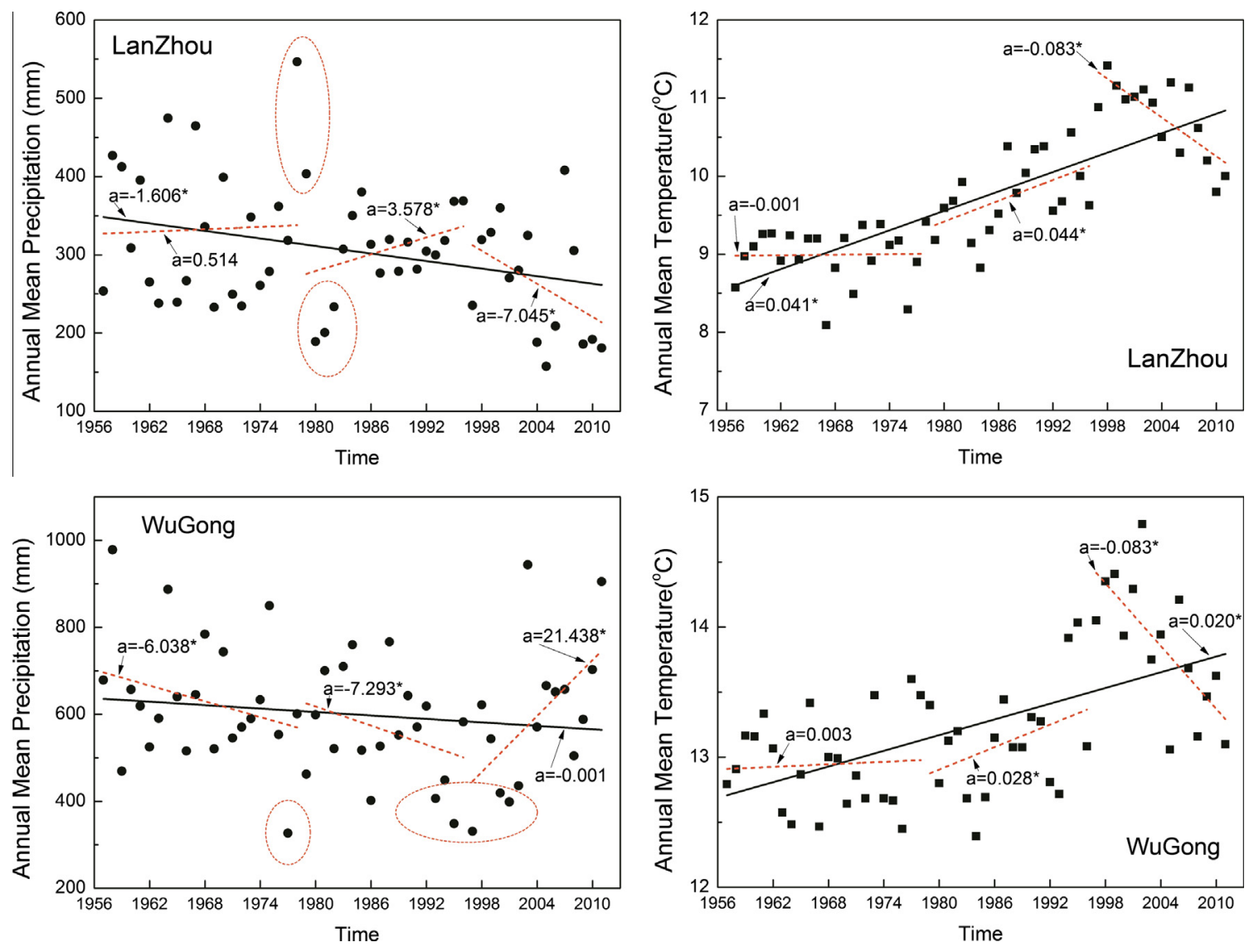

Fig. 10. Temporal changes of annual mean precipitation and temperature in LanZhou and WuGong from 1957 to 2012.

framework for the further modeling and prediction of drought behaviors on the Loess Plateau.

\section{Conclusions}

In this study, two multiscalar drought indices, the Standardized Precipitation Index (SPI) and the Standardized Precipitation-Evapo transpiration Index (SPEI), were used to identify the regional spatiotemporal patterns of drought conditions across the Loess Plateau region of China over the last half century, from 1957 to 2012. Influenced by the varying local topography and landscapes, the precipitation and temperature showed moderate to strong spatial and temporal variations, which would have profound impacts on the spatiotemporal characteristics of drought conditions. Based on the principal component analysis of the SPI and SPEI time series at the 12-month time scale for 54 meteorological stations, the whole region could be divided into four subregions with different drought characteristics, and the corresponding representative meteorological stations were determined for future drought monitoring. After removing the significant autocorrelations in the SPI and SPEI time series, the temporal trends of drought severity detected with the Mann-Kendall test were mapped for the entire region. Based on the SPI time series at the 12-month time scale, areas with significant increasing trends of drought severity were identified located in the southwest, central and east parts of the region. The intensity of the increasing trend of drought severity based on the SPEI was weaker that than based on the SPI time series. Moreover, the area with a significant increasing trend of drought severity based on the SPEI was only found in the southwest of the region, which was much smaller than that based on the SPI. Two areas located in the north HeTao Plain and very west of the region showed possible decreasing trends of drought severity, as indicated by the SPEI time series at the 12-month time scale. The temporal behaviors of the drought frequency from January to December differed with the different time scales and levels of drought severity. More temporal variations of the monthly drought frequency along the 12 months were found based on the SPEI than that based on the SPI. Moreover, the regional distribution of the drought frequency based on the SPEI at the 12-month time scale (value <-1.0) were plotted for the 12 months in a year. Generally, the drought frequency spatially decreases from the southeast to northwest and was higher in the middle of the winter (January), late spring (May) and early summer (June and July). The drought-hit area also changed with time, mostly dominating the central and northwest areas of the region. The drought behaviors identified by the SPI and SPEI also changed with different time scales, which could help recognize different types of drought related to various usable water resources. Evident differences were also found among the drought characteristics identified by the SPI, SPEI and the sc-PDSI. Under global climate change scenarios, the SPEI is suggested to be a robust index for regional drought monitoring and analysis due to its multiscalar nature, simplicity of form, low data requirement, and the ability to identify the effects of temperature on drought conditions. Further efforts should be made in regional drought modeling and prediction by considering the spatiotemporal variations of climate and their effects on drought conditions.

\section{Acknowledgements}

This research was supported by the National Natural Science Foundation of China (No. 41401241), National Natural Science 
Foundation of JiangSu Province of China (BK20140724). Authors wish to thank the editor and reviewers for their valuable comments and suggestions.

\section{References}

Abramowitz, M., Stegun, I.A., 1965. Handbook of Mathematical Functions. Dover Publications, New York.

Allen, R.G., Smith, M., Pereira, L.S., Perrier, A., 1994. An update for the calculation of reference evapotranspiration. ICID Bull. Int. Comm. Irrig. Drain., 35-92

Ahmad, M.I., Sinclair, C.D., Werritty, A., 1988. Log-logistic flood frequency analysis. J. Hydrol. 98, 205-224.

Box, G.E.P., Jenkins, G.M., Reinsel, G.C., 1994. Time Series Analysis: Forecasting and Control, third ed. Holden-Day.

Chen, F.H., Huang, W., Jin, L.Y., Chen, J.H., Wang, J.S., 2011. Spatiotempora precipitation variations in the arid Central Asia in the context of global warming. Sci. China, Earth Sci. 54 (12), 1812-1821.

Dai, A.G., Trenberth, K.E., Karl, T.R., 1998. Global variations in droughts and wet spells: 1900-1995. Geophys. Res. Lett. 25, 3367-3370.

Du, J., Li, C., La, B., Luobuciren, Liao, J., 2009. Climate changes of terrestrial surface humid index and its impact factors over Tibet in recent 35 years. Acta Meteorol. Sin. 67 (1), 158-164 (in Chinese with English abstract).

Gocic, M., Trajkovic, S., 2013. Analysis of precipitation and drought data in Serbia over the period 1980-2010. J. Hydrol. 494, 32-42.

Goovaerts, P., 1999. Geostatistics in soil science: state-of-the-art and perspectives. Geoderma 89, 1-45.

Guttman, N.B., Wallis, J.R., Hosking, J.R.M., 1992. Spatial comparability of the palmer drought severity index. Water Resour. Bull. 28, 1111-1119.

Guttman, N.B., 1999. Accepting the standardization index: a calculation algorithm. J. Am. Water Resour. Assoc. 35, 311-322.

Guttman, N.B., 1997. Comparing the palmer drought index and the standardized precipitation index. J. Am. Water Resour. Assoc. 34, 113-121.

Hamed, K.H., Rao, A.R., 1998. A modified Mann-Kendall trend test for autocorrelated data. J. Hydrol. 204, 182-196.

Hayes, M.J., Svoboda, M.D., Wilhite, D.A., Vanyarkho, O.V., 1999. Monitoring the 1996 drought using the standardized precipitation index. Bull. Am. Meteorol Soc. $80,429-438$.

Heddinghaus, T.R., Sabol, P., 1991. A review of the palmer drought severity index and where do we go from here? In: Proc. 7th Conf. on Applied Climatology, September 10-13, 1991. American Meteorological Society, Boston, Massachusetts, pp. 242-246

He, X.B., Li, Z.B., Hao, M.D., Tang, K.L., Zheng, F.L., 2003. Down-scale analysis for water scarcity in response to soil-water conservation on Loess Plateau of China. Agric. Ecosyst. Environ. 94, 355-361.

Heim, R.R., 2002. A review of twentieth-century drought indices used in the United States. Bull. Am. Meteorol. Soc. 83, 1149-1165.

Hu, Q. Willson, G.D., 2000. Effect of temperature anomalies on the palmer drought severity index in the central United States. Int. J. Climatol. 20, 1899-1911.

IPCC, 2012. Summary for Policymakers. In: Field, C.B., Barros, V., Stocker, T.F., et al. (Eds.), Managing the Risks of Extreme Events and Disasters to Advance Climate Change Adaptation. A Special Report of Working Groups I and II of the Intergovernmental Panel on Climate Change. Cambridge University Press Cambridge and New York, pp. 1-19.

Jiang, D.B., Sun, M.F., Wei, R.Q., Liu, B., 2009. Variation and projection of drought and wet conditions in Xinjiang. Chin. J. Atmos. Sci. 33 (1), 90-98 (in Chinese with English abstract).

Jiang, R., Xie, J., He, H., Luo, J, Zhu, J., 2014. Use of four drought indices for evaluating drought characteristics under climate change in Shananxi, China: 1951-2012. Nat. Hazards. http://dx.doi.org/10.1007/S11069-014-1468-x.

Jones, P.D., Moberg, A., 2003. Hemispheric and large-scale surface air temperature variation: an extensive revision and an update to 2001. J. Climate 16, 206-223.

Kendall, M.G., 1975. Rank Correlation Methods. Griffin, London.

Keyantash, J., Dracup, J.A., 2002. The quantification of drought: an evaluation of drought indices. Bull. Am. Meteorol. Soc. 83, 1167-1180.

Li, B., Su, H., Chen, F., Wu, J., Qi, J., 2013. The changing characteristics of drought in China from 1982 to 2005. Nat. Hazards 68, 723-743.

Li, Z., Zheng, F.L., Liu, W.Z., 2012. Spatiotemporal characteristics of reference evapotranspiration during 1961-2009 and its projected changes during 2011 2009 on the Loess Plateau of China. Agric. For. Meteorol. 154-155, 147-155.

Liu, Y.H., Xu, Y., Liu, Y., 2012. Population growth and temporal-spatial differentiation in the Loess Plateau region in the last 2000 years. Progr. Geogr. 31 (2), 156-166 (in Chinese with English abstract).

Lloyd-Hughes, B., Saunders, M.A., 2002. A drought climatology for Europe. Int. J Climatol. 22, 1571-1592.

Ma, Z.G., 2005. Dry/wet variation and its relationship with regional warming in arid-regions of northern China. Chin. J. Geophys. 48 (5), 1011-1018 (in Chinese with English abstract).

Mann, H.B. 1945. Nonparametric tests against trend. Econometrica 13, 245-259.

McKee, T.B., Doesken, N.J., Kleist, J., 1993. The relationship of drought frequency and duration to time scales. In: Eighth Conference on Applied
Climatology. American Meteorological Society, Anaheim, CA, pp. 179-184 (preprints).

Nielsen, D.R., Bouma, J., 1985. Soil Spatial Variability. Pudoc, Wageningen.

North, G.R., Bell, T.L., Cahalan, R.F., 1982. Sampling errors in the estimation of empirical orthogonal functions. Monthly Weather Rev. 110, 699-706.

Núñez, J., Rivera, D., Oyarzún, R., Arumí, J.L., 2014. On the use of standardized drought indices under decadal climate variability: critical assessment and drought policy implications. J. Hydrol. 517, 458-470.

Ostwald, M., Chen, D., 2006. Land-use change: impacts of climate variation and policies among small-scale farmers in the Loess Plateau, China. Land Use Policy 23, 361-371.

Palmer, W.C., 1965. Meteorological drought. Research Paper No. 45, Weather Bureau, Washington, D.C., 58pp.

Potop, V., Mo, M., Soukup, J., 2012. Drought evolution at various time scales in the lowland regions and their impact on vegetable crops in the Czech Republic. Agric. For. Meteorol. 156, 121-133.

Raziei, T., Saghafian, B., Paulo, A.A., Pereira, L.S., Bordi, I., 2009. Spatial patterns and temporal variability of drought in western Iran. Water Resour. Manage. 23, $439-455$.

Sheffield, J., Wood, E.F., 2008. Projected changes in drought occurrence under future global warming from multi-model, multi-scenario, IPCC AR4 simulations. Climate Dyn. 31, 79-105.

Shen, S.H., Zhang, F.M., Sheng, Q., 2009. Spatio-temporal changes of wetness index in China from 1975 to 2004. Trans. CSAE 25 (1), 11-15 (in Chinese with English abstract).

Shi, H., Shao, M.A., 2000. Soil and water loss from the Loess Plateau in China. J. Arid Environ. 45, 9-20.

Shi, Y.F., 2003. Assessment on the Climate Change from Warm-Dry to Warm-Wet in Northwest China. China Meteorological Press, Beijing (in Chinese).

Solomon, S., Qin, D., Manning, M., Marquis, M., Averyt, K., Tignor, M.M.B., Miller, H. L., Jr., Chen, Z. (Eds.), 2007. Climate Change 2007: The Physical Science Basis. Cambridge University Press, 996 pp..

Steinemann, A., 2003. Drought indicators and triggers: a stochastic approach to evaluation. J. Am. Water Resour. Assoc. 39 (5), 1217-1233.

Syed, T.H., Famiglietti, J.S., Rodellm, M., Chen, J., Wilson, C.R., 2008. Analysis of terrestrial water storage changes from GRACE and GLDAS. Water Resour. Res. 44. W02433. http://dx.doi.org/10.1029/2006WR005779.

Tabari, H., Talaee, P.H., Nadoushani, S.S.M., Willems, P., Marchetto, A., 2014. A survey of temperature and precipitation based aridity indices in Iran. Quaternary Int. 345, 158-166.

Vicente-Serrano, S.M., Beguería, S., López-Moreno, J.I., 2010. A multiscalar drought index sensitive to global warming: the standardized precipitation evapotranspiration index. J. Climate 23, 1696-1718.

von Storch, H., Zwiers, F.W., 1999. Statistical Analysis in Climate Research. Cambridge University Press, Cambridge, p. 484.

Wang, Y.Q., Shao, M.A., Zhu, Y.J., Liu, Z.P., 2011. Impacts of land use and plant characteristics on dried soil layers in different climatic regions on the Loess Plateau of China. Agric. For. Meteorol. 151, 437-448.

Wang, Y.Q., Shao, M.A., Liu, Z.P., Zhang, C.C., 2014a. Prediction of bulk density of soils in the Loess Plateau of China. Surv. Geophys. 35, 395-413.

Wang, Y.Q., Shao, M.A., Han, X.W., Liu, Z.P., 2014b. Spatial variability of soil parameters of the van Genuchten model at a regional scale. Clean-Soil, Air, Water 42, 1-8.

Wells, N., Goddard, S., Hayes, M.J., 2004. A self-calibrating palmer drought severity index. J. Climate 15, 2335-2351.

Western, A.W., Blöschl, G., 1999. On the spatial scaling of soil moisture. J. Hydrol. 217, 203-224.

Wilhite, D.A., 1993. Drought assessment, management and planning: theory and case studies. Natural Resource Management and Policy Series, vol. 2. Kluwer, 293 pp..

Wilhite, D.A., Glantz, M.H., 1985. Understanding the drought phenomenon: the role of definitions. Water Int. 10, 111-120.

Wu, H., Hayes, M.J., Wilhite, D.A., Svoboda, M.D., 2005. The effect of the length of record on the standardized precipitation index calculation. Int. J. Climatol. 25, 505-520.

Yao, Y.B., Wang, R.Y., Yang, J.H., Yue, P., Lu, D.R., Xiao, G.J., Wang, Y., Liu, L.C., 2013. Changes in terrestrial surface dry and wet conditions on the Loess Plateau (China) during the last half century. J. Arid Land 5 (1), 15-24.

Zhang, B., Wu, P., Zhao, X., Wang, Y., Wang, J., Shi, Y., 2012. Drought variation trends in different subregions of the Chinese Loess Plateau over the past four decades. Agric. Water Manage. 115, 167-177.

Zhang, T., Zhang, B., Zhang, M., Liu, X., Sui, L., An, M., 2012. Spatiotemporal pattern of drought in Loess Plateau of Gansu Province, Northwest China in 1961-2010. Chin. J. Ecol. 31 (8), 2066-2074 (in Chinese with English abstract).

Zhao, X., Wu, P., 2013. Meteorological drought over the Chinese Loess Plateau: 1971-2010. Nat. Hazards 67, 951-961.

Zipper, S.C., Loheide II, S.P., 2014. Using evapotranspiration to assess drought sensitivity on a subfield scale with HRMET, a high resolution surface energy balance model. Agric. For. Meteorol. 197, 91-102.

Zou, X., Zhai, P., Zhang, Q., 2005. Variations in droughts over China: 1951-2003. Geophys. Res. Lett. 32, L04707. 